University of Windsor

Scholarship at UWindsor

$1-1-2019$

\title{
Examining Factors, Supports, and Transitional Resources among Students Attending Agency Schools in Southwestern Ontario
}

\author{
Gelsea Pizzuto \\ University of Windsor
}

Follow this and additional works at: https://scholar.uwindsor.ca/etd

\section{Recommended Citation \\ Pizzuto, Gelsea, "Examining Factors, Supports, and Transitional Resources among Students Attending Agency Schools in Southwestern Ontario" (2019). Electronic Theses and Dissertations. 7760. https://scholar.uwindsor.ca/etd/7760}

This online database contains the full-text of PhD dissertations and Masters' theses of University of Windsor students from 1954 forward. These documents are made available for personal study and research purposes only, in accordance with the Canadian Copyright Act and the Creative Commons license-CC BY-NC-ND (Attribution, Non-Commercial, No Derivative Works). Under this license, works must always be attributed to the copyright holder (original author), cannot be used for any commercial purposes, and may not be altered. Any other use would require the permission of the copyright holder. Students may inquire about withdrawing their dissertation and/or thesis from this database. For additional inquiries, please contact the repository administrator via email (scholarship@uwindsor.ca) or by telephone at 519-253-3000ext. 3208. 


\title{
EXAMINING FACTORS, SUPPORTS, AND TRANSITIONAL RESOURCES AMONG STUDENTS ATTENDING AGENCY SCHOOLS IN SOUTHWESTERN ONTARIO
}

By

\section{Gelsea Pizzuto}

\author{
A Thesis \\ Submitted to the Faculty of Graduate Studies \\ through the Faculty of Education \\ in Partial Fulfillment of the Requirements for \\ the Degree of Master of Education \\ at the University of Windsor
}

Windsor, Ontario, Canada

2019

(C) 2019 Gelsea Pizzuto 
EXAMINING FACTORS, SUPPORTS, AND TRANSITIONAL RESOURCES AMONG STUDENTS ATTENDING AGENCY SCHOOLS IN SOUTHWESTERN ONTARIO

by

\section{Gelsea Pizzuto}

APPROVED BY:

P. Phipps
Women's and Gender Studies
C. Cobb
Faculty of Education
G. Salinitri, Advisor
Faculty of Education

June 7, 2019 


\section{DECLARATION OF ORIGINALITY}

I hereby certify that I am the sole author of this thesis and that no part of this thesis has been published or submitted for publication.

I certify that, to the best of my knowledge, my thesis does not infringe upon anyone's copyright nor violate any proprietary rights and that any ideas, techniques, quotations, or any other material from the work of other people included in my thesis, published or otherwise, are fully acknowledged in accordance with the standard referencing practices. Furthermore, to the extent that I have included copyrighted material that surpasses the bounds of fair dealing within the meaning of the Canada Copyright Act, I certify that I have obtained a written permission from the copyright owner(s) to include such material(s) in my thesis and have included copies of such copyright clearances to my appendix.

I declare that this is a true copy of my thesis, including any final revisions, as approved by my thesis committee and the Graduate Studies office, and that this thesis has not been submitted for a higher degree to any other University or Institution. 


\begin{abstract}
Mental health challenges continue to rise amongst children, proving the need for successful school based mental health services. Agency schools can combine treatment and education in order to try and meet the diverse needs of students in-risk that are unable to succeed in community school settings. In conducting this study, I present and interpret the perspective of teachers for policy makers, administrators, and researchers to develop a deeper understanding of the structure and dynamics of day treatment programs and transitions, so that agency schools can continue to develop to meet the needs of students. In this qualitative case study, I investigated the lived experiences of teachers working in agency schools in a region in Southwestern Ontario. Semi-structured interviews were conducted, and the data was analyzed through Interpretative Phenomenological Analysis (IPA). Five themes emerged from an analysis of the data: 1) Teaching the Whole Child; 2) Communication; 3) Collaboration and Team Dynamics; 4) The Present Role of Parent(s) and/or Guardians; and 5) Successful and Adaptive Transition. The themes present a general conception of how teachers identify their role in agency schools while providing evidence of the success of day treatment programs and student transitions.
\end{abstract}

Key Works: risk; mental health; agency schools; teachers; interpretative phenomenological analysis (IPA) 


\section{DEDICATION}

I dedicate this thesis to every teacher and support staff that works in the education sector. May your compassion, empathy, and dedication allow you to continue to inspire your students to reach their highest potential. You are making a difference. 


\section{ACKNOWLEDGEMENTS}

I would like to express my deepest gratitude to my research advisor, Dr.

Geri Salinitri. You have provided me with so much guidance in all the work that I do. I look up to you in so many ways. Thank you for believing in me and challenging me to keep reaching. I look forward to continuing in the Ph.D. program with your guidance and mentorship.

I would also like to express gratitude to my internal department reader, Dr. Cam Cobb and my external reader, Dr. Pauline Phipps. Thank you looking through a different lens and providing feedback that helped me grow as a researcher. I truly appreciate your detailed feedback that helped to enhance the clarity of my writings. In addition, I would like to thank Dr. Glenn Rideout, Dr. Andrew Allen, Dr. Susan Holloway, and Mandy Turkalj for their ongoing support throughout my educational journey thus far.

I cannot express enough gratitude to my personal supports that have helped me persevere. To my parents, Anthony and Joanne, thank you for your patience, unconditional love, and support. You have given me such a beautiful life and truly sparked my love of learning. To my brother, Agostino, thank you for not only being the most amazing and protective brother, but for always being a wonderful friend. You always push me to think in a different way. To all of my nonni, thank you for all that you did to help raise me to be the person I am today.

To my best friends and sisters, Beckie and Alley, thank you for supporting me in everything that I do and encouraging me to always achieve my best. You 
two are the definition of beautiful inside and out and are constantly pushing me to be a better person. I am forever grateful for the two of you.

To Rea, thank you for your kindness, compassion, and being the most wonderful addition to all of our lives. Thank you to all of my family and friends who have provided me with so much support. I would not be where I am today without everything you do for me.

Lastly, I would like to thank all of the educators that participated in my research. May your passion continue to fuel your work as a teacher. You are doing amazing things for your students and are a true inspiration. 
DECLARATION OF ORIGINALITY ..........................................................

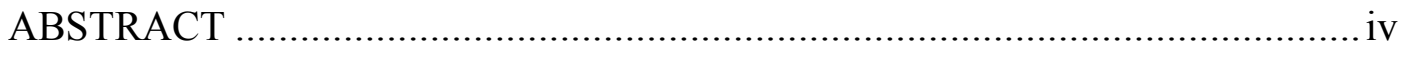

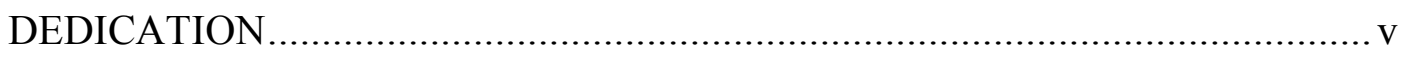

ACKNOWLEDGEMENTS........................................................................ vi

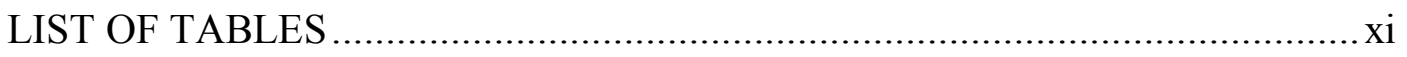

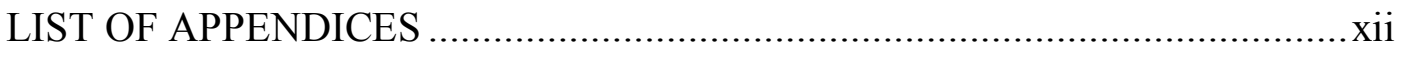

LIST OF ABBREVIATIONS/SYMBOLS ........................................................ii

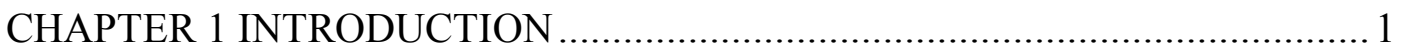

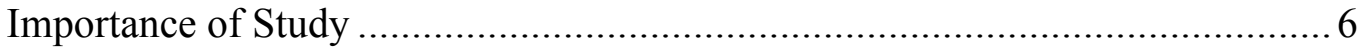

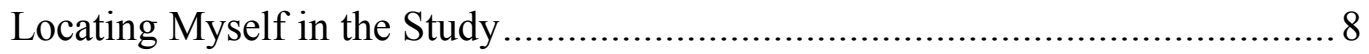

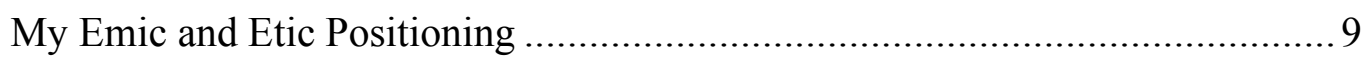

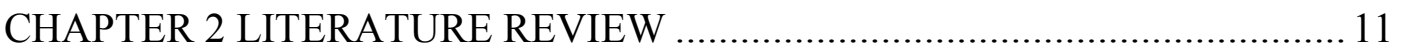

Education and its Function in Society ……………........................................ 11

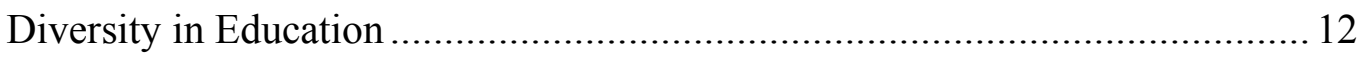

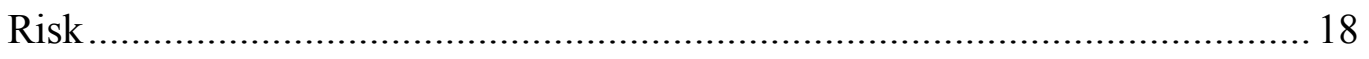

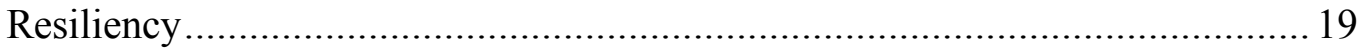

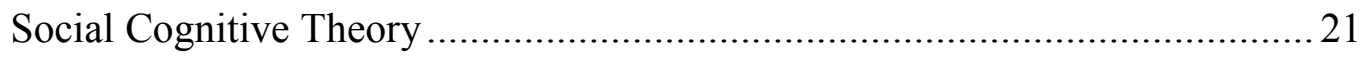

Social and Emotional Learning (SEL)........................................................... 24

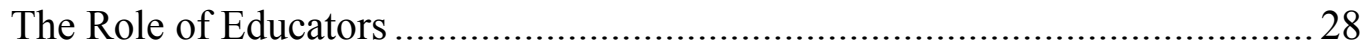

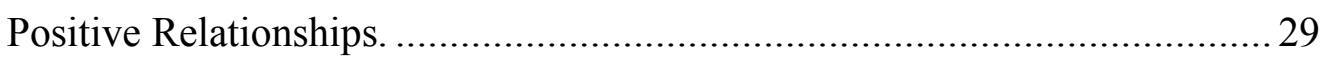

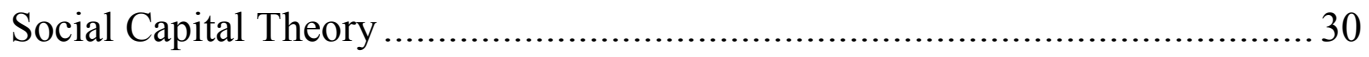

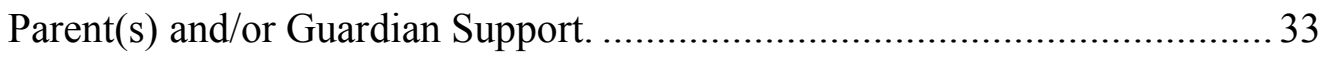

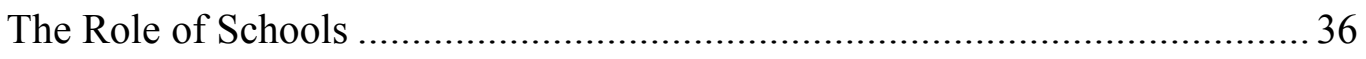

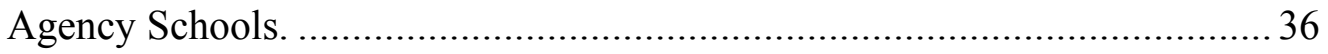

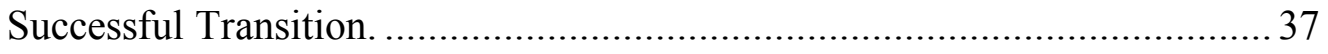




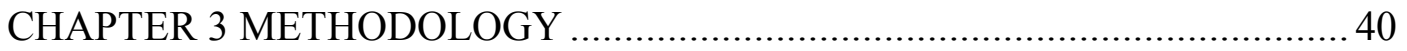

Interpretive Phenomenological Analysis .......................................................... 41

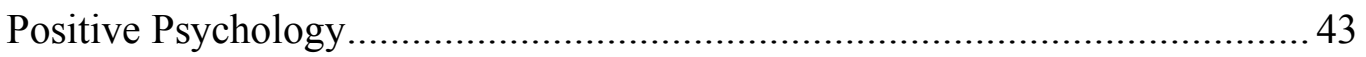

Selection Criteria and Recruitment ............................................................. 45

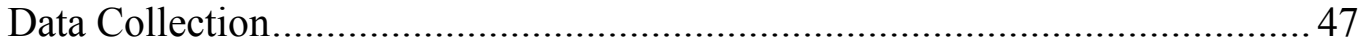

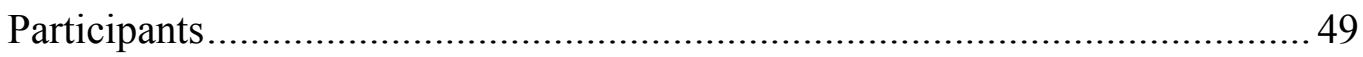

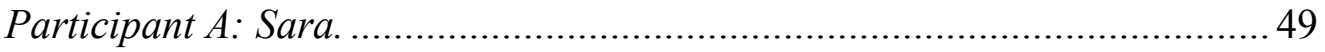

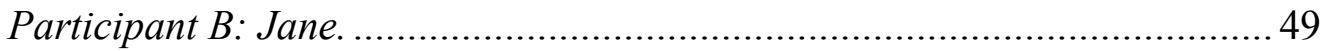

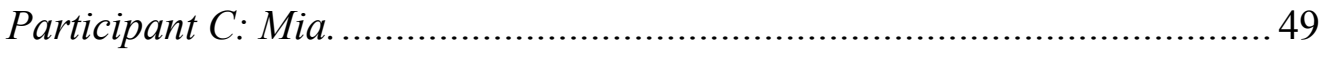

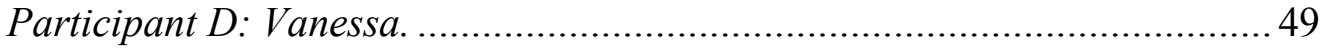

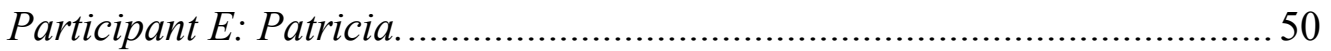

Participant F: Heather........................................................................ 50

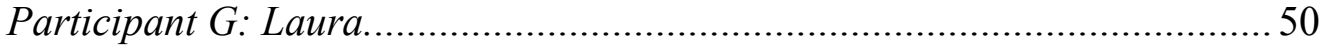

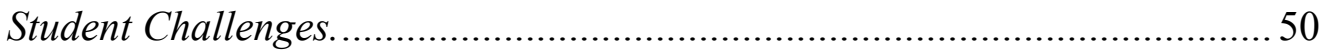

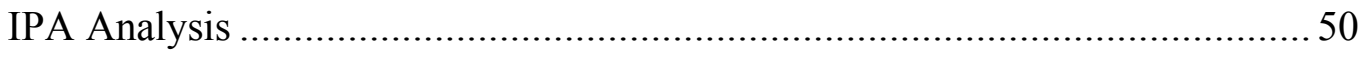

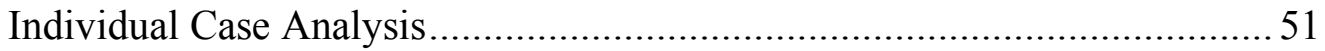

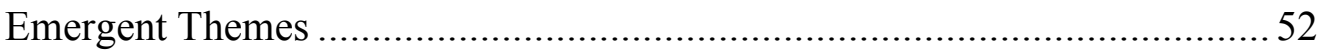

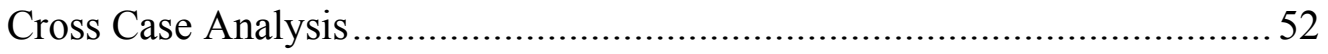

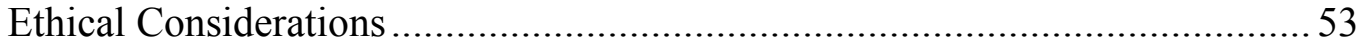

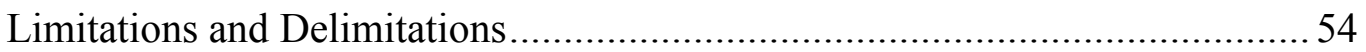

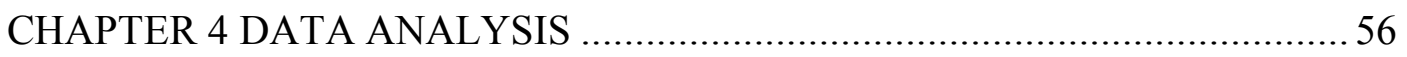

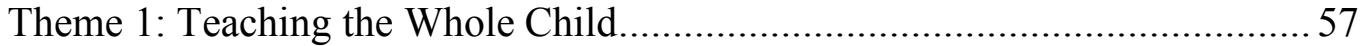

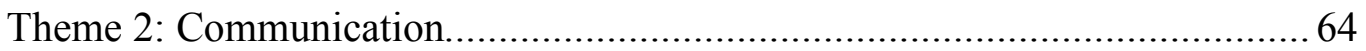

Theme 3: Collaboration and Team Dynamics ……………...............................69 69

Theme 4: The Present Role of Parent(s) and/or Guardians .............................. 72

Theme 5: Successful and Adaptive Transition................................................ 79

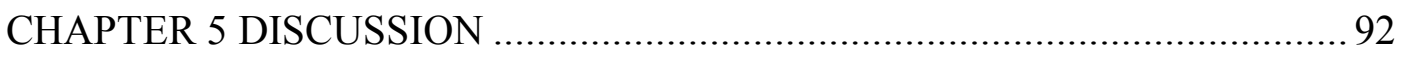

First Research Question ............................................................................. 93

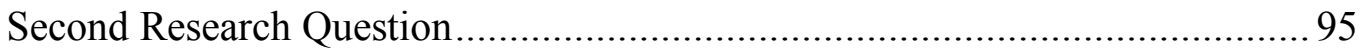

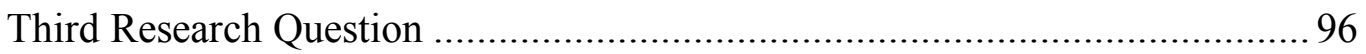




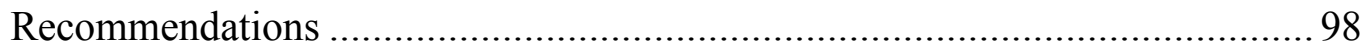

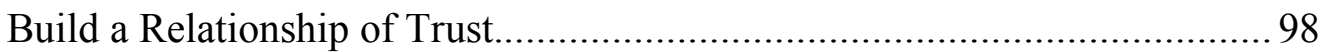

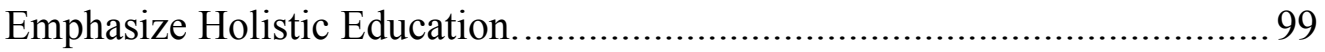

Knowledge of Agency School Environments. …………............................... 99

Suggestions for Future Research.................................................................... 100

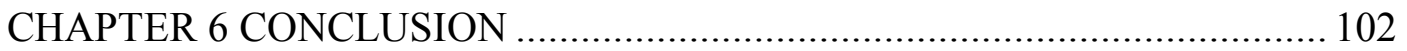

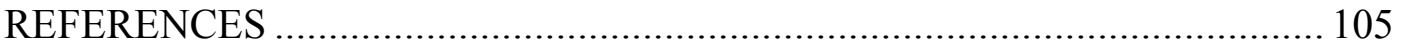

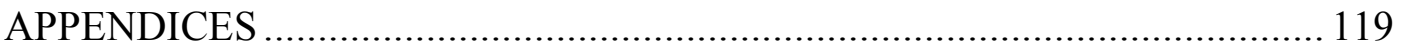

Appendix A: Definition of Key Terms...................................................... 119

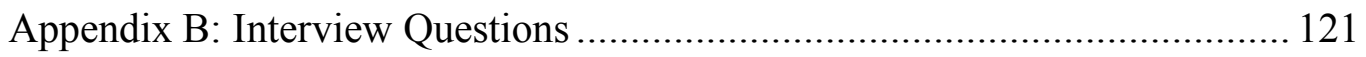

Appendix C: Ethics Approval ................................................................... 123

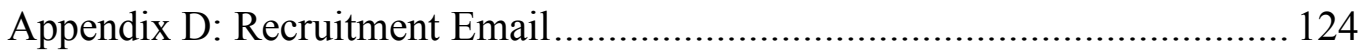

Appendix E: Letter of Consent to Participate in Research ............................... 126

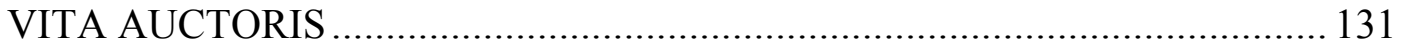




\section{LIST OF TABLES}

Table 1: Summary of Research Framework for this Study

Table 2: Steps for Conducting Interpretive Phenomenological Analysis 


\section{LIST OF APPENDICES}

Appendix A: Definition of Key Terms

Appendix B: Interview Questions

Appendix C: Ethics Approval

Appendix D: Recruitment Email

Appendix E: Letter of Consent 


\section{LIST OF ABBREVIATIONS/SYMBOLS}

CTCC

Educational Programs in Government-Approved Facilities

for Care, Treatment and Custodial or Correctional

CYW

Child and Youth Worker

IEP

Individualized Education Plan

IPA

Interpretive Phenomenological Analysis

OMCYS

Ontario Ministry of Children and Youth Services

OME

Ontario Ministry of Education

REB

Research Ethics Board

SCT

Social Cognitive Theory

SEL

Social and Emotional Learning 


\section{CHAPTER 1}

\section{INTRODUCTION}

There is growing concern around the gap in achievement levels amongst the increasingly diverse population of students, as well as an increase in the number of students who are dropping out of school before graduating (Gallagher, Malloy \& Ryerson, 2016; OME, 2010). Various individual, family, or school related factors place students at risk of not graduating. Some of these risk factors include, but are not limited to, those who are from minority groups, have various exceptionalities, live in poverty, and those who are not exposed to encouraging environments (Campie, Pakstis, Flynn, \& McDermott, 2015; Hughes \& Adera, 2006). Despite efforts to improve academic and overall achievement among students who are at risk of not graduating, a substantial gap exists between achievement levels among these students and others, specifically students experiencing difficulties among social, emotional, developmental and/or behavioural development (Brimblecombe et al., 2017; Hughes \& Adera, 2006; OME, 2019).

For the purpose of this research, social, emotional, developmental and behavioural development are defined as children's ability to express and regulate emotion in socially and appropriate ways, form close and secure adult and peer relationships, and explore the environment and learn (Darling-Churchill \& Lippman, 2016; Jones, Zaslow, Darling-Churchill \& Halle, 2016; Yates et al., 2008). Some of the characteristics and skills of positive social, emotional, developmental and behaviour development include, but are not limited to, emotion expression and management, empathy, perspective taking, self-confidence, as well as the ability to develop and maintain relationships with others (Darling-Churchill \& Lippman, 2016; Jones et al., 2016; Yates et al., 2008). 
Maladjustment in these domains may impede a child's ability to function in family, school, and other contexts (Darling-Churchill \& Lippman, 2016; Yates et al., 2008). These issues can be very complex; however, the following list gives a brief overview of some of the examples of issues that children and adolescents can be facing due to an influence of both environmental and biological factors (El-Radhi, 2015; Ogundele, 2018). Behaviour challenges can include oppositional defiance disorder, conduct disorder and attention deficit hyperactive disorder; conduct disorders, which are often referred to as antisocial behaviours, can include aggression and theft; emotional problems can include depression, anxiety, and post-traumatic stress disorder; and developmental disorders can include intellectual disability and speech/language delay (El-Radhi, 2015; Ogundele, 2018).

The prevalence of mental health issues is also on the rise amongst children and adolescents. According to the MHASEF Research Team (2015) as many as 1 in 5 children and youth in Ontario will experience some form of mental health problems. Some common mental illnesses that affect children and adolescents include, but are not limited to, anxiety disorder, attention-deficit disorder, conduct disorder, depression, bipolar disorder, schizophrenia, and suicide (MHASEF Research Team, 2015). The prevalence of these issues is even higher amongst students who are at risk of not graduating; further compromising their chances of success (Brimblecombe et al., 2017).

Students can be deemed "at-risk", "in-risk", or "high-risk" when they lack resiliency skills necessary to overcome various risk factors. These terms are often used interchangeably to address the degree of intervention and support required for students at risk of academic failure (Campie et al., 2015; Hughes \& Adera, 2006; McWhirter et al., 
2017). Although this is terminology used by researchers and professionals in the field of education and social work, many individuals would argue that this is a deficit view of thinking that can be harmful to students (Hartwick \& Kubisiak, 2014). Specifically, the term "at-risk" is used regularly in education policy discussions, news articles, and by professionals in education. Students attending alternative education in agency schools would be defined as "in-risk", as they are currently unable to succeed in mainstream schooling due to various characteristics or conditions. When these terms are used effectively, they can be used to help identify risk and protective factors to help mitigate harm to students. In educational research and practice, these risk terms are commonly used to identify students who do not perform well in traditional education settings, however often times these risk factors that determine this status are often out of the control of the student and their families. The purpose of the terms is to suggest a focus on prevention and intervention for students, however it is argued that these terms can place harsh labels on students that perpetuate deficits (Hartwick \& Kubisiak, 2014). I have decided to use this terminology in my research to keep consistent with the language used by current policy, as well as the professionals used in my research. However, I understand the implications of the terminology and use it sparingly.

There are currently numerous programs and supports in place within local school boards to reduce or alleviate risk factors and issues students may be facing, such as school social workers, child and youth workers, student success teachers, as well as alternative forms of education such as agency schools. When children and adolescents are dealing with serious social, emotional, developmental, and/or behavioural issues that 
need more support than their own school can offer, they may be assessed to attend day treatment in an agency school.

An agency school blends education with day treatment ${ }^{1}$ for individuals with serious mental, emotional, developmental and/or behavioural issues (OME, 2017; OME, 2019). The Ontario Ministry of Education (OME) describes these alternative schools as "Educational Programs in Government-Approved Facilities for Care, Treatment and Custodial or Correctional (CTCC) Facilities" (2019). In Ontario, these settings were previously referred to as Sections 23 classrooms because this is the number and section of the funding regulation that allows these schools to receive provincial funding (OME, 2009). Under the education act (subsection 171(1), paragraph 40), school boards have the authority to conduct education in CTCC facilities (e.g. community agencies, youth justice centres, mental health and/or hospital settings) where the school board provides the educational programming and the facility provides the care, treatment, and/or rehabilitation (OME, 2017).

These services are designed to prevent movement to a more intensive level of care (OME, 2017). Students attend the day treatment program during regular school hours, instead of their community school. Placement is considered temporary, and the average student is usually in a program for a year and then re-integrated back into their community school (OME, 2017). The goal for the interdisciplinary team working in agency school settings is to bring together mental health professionals and educators to

\footnotetext{
${ }^{1}$ Day treatment is a partial hospitalization program joint with education for those individuals with serious mental, emotional, developmental, and/or behavioural issues (OME, 2017, OME, 2019). These services are designed to prevent movement to a more intensive level of care (OME, 2017; OME, 2019). Although treatment is a medical term, it is used in this research to keep consistent with policy documents in Ontario, as well as the language used by the professionals interviewed in this research.
} 
coordinate different methodologies and strategies to provide for the diverse needs of students (OME, 2019; Pazaratz, 1998; Stephan, Sugai, Lever \& Connors, 2015). Some of these professionals include child and youth workers, special education teachers, social workers, psychologists, child psychiatrists, nurses, family physicians, and various therapists (OME, 2017). These treatment programs offer a variety of different services designed to support children, youth and families such as crisis stabilization, diagnostic, assessment, and intervention.

Each school board has its own process for determining admission into these programs, and psychological testing is often required to determine how a student could benefit from this type of setting. Referral is normally carried out by school staff such as a teacher or principal who is referring an identified student to their respective board liaison to discuss the process and request a referral package from the agency schools' committee (OME, 2019). Sources of referral will complete a package, and the agency school committee will contact the respective school to support the application process (OME, 2019). The families of the student are then required to complete the application process to be admitted into the programs. There are a series of minimum expectations of intake and eligibility required by the OME (2019) and the Ontario Ministry of Children and Youth Services (OMCYS) (2015). A clear intake process must be developed and documented for families to have access to and the student's needs and urgency of intervention must be assessed where preliminary service options are communicated to families (OMCYS, 2015). When there is a waitlist for service, students and families will be provided with information and supports to help them while waiting such as other community services they can access (OMCYS, 2015). 
Day treatment is regarded as a resocialization process for students to successfully transition back into their community school. Inclusion among peers is pivotal to students' social-emotional development (Acramidis et al., 2000), and thus the socialization process is equally as necessary when a child returns from an agency school. For students who are facing risk factors, they tend to conduct themselves differently from their peers and are thus isolated socially. By removing students from the standard classroom, it is debatable whether or not this promotes inclusion by teaching strategies to improve behaviour upon return, or if it pervades pre-existing social isolation (Acramidis et al., 2000). Some definitions of inclusion state that those with exceptionalities should learn alongside their peers, while others deem this to be a hindrance to the inclusionary process (Acramidis et al., 2000; Claymore, 2017). Additionally, teachers' attitudes towards inclusion and their ability to welcome students back into the classroom are correlated to the overall success of students. As such, it was important to my research to investigate the response of educators and their views on the reintegration and inclusionary processes.

\section{Importance of Study}

Providing every student with an equitable opportunity for success is one of the stated goals outlined by Ontario's publicly funded education system (OME, 2009). Although public education is provided to individuals of all backgrounds, students who are living with additional challenges and risk factors are faced with much lower chances of success (Campie et al., 2015; Hughes \& Adera, 2006). The diversity of students considered in-risk is quite extensive, however the vastness of this group is markedly unrepresented in policy and programs intended to address the challenges being faced. Many programs group students in-risk into one category, even though their circumstances 
may range from substance abuse and low-socioeconomic status, to developmental exceptionality (Hughes \& Adera, 2006; OME, 2009). Therefore, the experiences, needs, and programs designed to help these students succeed should be equally as diverse. More research should be conducted in agency schools to understand the unique challenges that may be faced by the students attending these programs. Furthermore, I do not know of any completed studies encompassing the perspectives of teachers working in agency school settings, specifically in the Ontario context. By conducting this study, current gaps in research in Ontario agency school settings will be explored.

Additionally, analyzing educational views on the programs available to assist the transition back to community schools will lead to an evaluation of what constitutes as a successful program and transition. Agency schools are reportedly saturated with supports and programs (OME, 2019), and thus it will be interesting and important to find if or how these programs and supports are adjusted in community schools. Bennett, Weber and Dworet (2013) explain that a hindering factor to educational success is the loss of consistency children face once they return to their community school. Programs that foster social and emotional health or coping skills sometimes end once the child is reintegrated, and rather replaced with demands of academic achievement instead (Bennett et al., 2013; Hughes \& Adera, 2006).

In conducting this research study, I sought to understand what resources and strategies are currently in place that help to make these programs successful. I also explored the challenges facing these students through the perspectives of teachers, as well as the efforts of the public education system to help these students reach academic and overall success during their transition back into community schools. 
The purpose of this research is to present and interpret the perspective of teachers for policy makers, administrators, and researchers to develop a deeper understanding of the structure and dynamics of day treatment programs and transitions, so that agency schools can continue to develop to meet the needs of students in-risk.

Research on the topic of students and their transition from agency schools to community schools requires a complex investigation into several factors that influence success. I started developing my interview protocol, which resulted in the following overarching questions. As such, the following research questions and sub questions aim to address these complexities by gaining first-hand accounts, opinions, and insight from classroom teachers:

1. How do teachers perceive their role working with students who are receiving treatment in agency schools?

2. How does their role affect the academic and overall achievement outcomes for students in-risk?

3. What types of programs and strategies are in place for a successful transition from treatment in an agency school, back into a community school?

Sub Questions:

- How effective is the transition into community schools?

\section{Locating Myself in the Study}

I locate myself in this study in a manner that is socially aware and knowledgeable of the complexity of this current topic in education. My interest and relation to this study is rooted in my own experiences as an elementary occasional teacher who has been exposed to social inequalities and risk factors amongst students. I acknowledge my own 
limitations as a researcher, due to my position as a Caucasian, socially-advantaged, and Canadian-born individual. In my recent experience supply teaching in an agency school, I was exposed to social factors effecting youth and their success, which I myself cannot fully relate to on a personal level. I have also volunteered and taken part in after school programs and school board events, where I have been able to assist families and children who may face discrimination, lack resources, as well as are from diverse cultures in an unfamiliar environment. I volunteered in these positions to increase my capacity as a teacher and a scholar in order to better understand variables affecting students and families. These experiences expanded my knowledge on a more personal level and fostered a sense of social responsibility and empathy to assist youth limited by these factors in transitioning back to community schools.

\section{My Emic and Etic Positioning}

Firstly, I offer my experience as a former pre-service teacher at the University of Windsor, as well as an Early Childhood Education graduate. I have experienced courses in teacher education, child development and social justice, as well as become exposed to diverse races, ethnicities, and social minorities in our current schools. These areas of study heightened my educational and social understanding of political and social limitations faced by individuals in society, and the ramifications this has for youths' development and academic progress. During my time at the Faculty of Education, I have observed and gained experience working in Windsor and Essex County and being a part of the team countering various social and economic limitations, such as poverty, housing instability, stress, malnutrition, varying and instable parental work schedules, and inadequate access to healthcare. While completing my teacher education studies, I 
participated in the Leadership Experience for Academic Direction (LEAD) course, wherein I was exposed to working with students and families facing the types of limitations listed above. I recall numerous instances where these limitations forced academics to become secondary importance because students were faced with issues such as frequently coming to school late, absenteeism, feeling hungry, not having healthy food options, not sleeping enough, and not receiving support with struggling homework or academics. During my time in this course, I worked with educators and parents to offer supports otherwise lacking from the core curriculum and available programs. Some of these supports included afterschool homework programs, breakfast and snack programs, and mindfulness programs.

As a current occasional teacher, I have witnessed and had to intervene when a student's inability to cope or their behavioral challenges interrupted the classroom and rendered them unfit to stay, thus requiring additional support and intervention from support staff such as a CYW. These students face isolation from peers and limited social and emotional development. Observing the struggles faced by these students first-hand is one of the greatest motivations for my research. While these experiences have provided me with insight into the risk factors faced by many students, I acknowledge that I am, in many ways, an outsider in this area as I compare the advantages that helped me succeed in school. 


\section{CHAPTER 2}

\section{LITERATURE REVIEW}

The following literature review expands on various research elements of education, educators, agency schools, and their impact on students in-risk. First, diversity in education and the need for social and emotional learning is described. Risk and resiliency amongst students are outlined, as well as the role that schools and educators can have to help students overcome risk and reach success. Lastly, this literature review describes the theoretical framework guiding this study, which consists of social capital theory and social learning theory. These theories assist in the formulation of interview questions and guide in analyzing the significance of the responses provided. In conducting this review of the literature, I sought to understand what current research has to say about the various elements required to support students attending agency schools, as well as during their transition back into their community schools.

\section{Education and its Function in Society}

Education is the sum of experiences, fact, and thought that an individual has gained over a lifetime (Richmond, 1975; Wood, 2011). Education is a lifelong process that deals with both the gaining of knowledge and the development of character and is not limited to a classroom or formal instruction (Richmond, 1975; Wood, 2011).

Schooling is the formal process associated with education that takes place in elementary, secondary, and post-secondary institutions (Richmond, 1975). A significant dichotomy exists between schooling and education. Although it is impossible to think of one without the other, education is so much more than just the material that we learn in school. Schooling refers to a place intended to help prepare individuals for work and society, 
whereas education refers to the lifelong process preparing the mind with knowledge, understanding, and skills (Richmond, 1975; Wood, 2011). Schools are responsible for formally teaching knowledge, specialized skills, norms, beliefs, as well as transmitting and refining cultural values (Wood, 2011).

Educators strive to develop the abilities and creativity of each individual with the end goal of leading students to become functional members of society (Mishra, 2016; Wood, 2011). Educators take on an important role in the perpetuation of society through finding a way to preserve knowledge, belief, and core values (e.g. respect for authority, punctuality, honesty, repression of aggression, etc.), while also providing opportunities for change and improvement by creating a pathway for new values to be incorporated into existing culture (Mishra, 2016). Schooling in Canada comprises of both public and private primary and secondary schools. Private schools are partly funded through tuition paid by parents, whereas public schools are fully funded by taxpayers. For the purpose of this research, only publicly funded school will be referenced.

\section{Diversity in Education}

Developing an understanding of diversity in schools is an important part of an educator's role to ensure the success of all students (Aronson \& Laughter, 2016; Swartz, 2017; Taylor, Oberle, Durlak, \& Weissberg, 2017). Student success encompasses a variety of interconnected components, measurable beyond academic achievement alone.

When a student is successful, he or she feels confident and capable to achieve present and future goals, academically, as well as socially and personally. Students are then able to develop a positive self-concept, express happiness and satisfaction, engage in the classroom community, create meaningful relationships with peers and adults, as well as 
fulfill the basic expectations of the core curriculum, to the best of their ability. The term diversity describes all the ways in which individuals are both similar and different from one another (Kinsella \& Senior, 2008). Teachers must create a classroom environment where all students feel safe and accepted despite differences, while also ensuring all students have equitable learning opportunities for academic and overall success (Swartz, 2017; Taylor et al., 2017). There have been significant and rapid changes amongst the demographic makeup of Canada around immigration, growth in the Aboriginal population, and rural/urban migration, which is altering the cultural, linguistic, ethnic, mental health, and socioeconomic characteristics of Ontario public schools (Trypuc \& Heller, 2008).

Multicultural education emerged to address various educational inequities among students based on their cultural characteristics and circumstances (Bennett, 1995). Multicultural education is defined as an approach for transforming education based on every student deserving equal opportunity and access to knowledge that will make them competent members of society regardless of origins, gender, sex, disability, and race (Bennett, 1995; Banks 1995; Levinson, 2009). Goals of multicultural education include increasing diversified student exposure, promoting social justice and equity, fostering children's autonomy, and enabling all students to succeed (Aronson \& Laughter, 2016; Levinson, 2009; Richards et al, 2007). Banks (1995) and Bennett (1995) believe that the structural organization of the school system is designed to the advantage of the dominant group; the dominant group being white, able-bodied, and middle class. According to those who hold this view, systematic changes are needed in education in order to 
establish equity and equal opportunity for all students to reach success (Aronson \& Laughter, 2016; Levinson, 2009; Swartz, 2017).

Culturally responsive practice emerged from multicultural education as a way to describe teachers who can understand how all students learn differently, and that these differences may be connected to factors such as background, language, and family structure. (Gay, 2002). Culturally responsive teaching is defined by Gay (2002) as "using the cultural characteristics, experiences, and perspectives of ethnically diverse students as conduits for teaching them more effectively" (p. 106). Culturally responsive practice is a student-centered approach to teaching, where students' unique characteristics are identified as strengths and used to promote a sense of achievement and well-being. It is divided into three functional dimensions: (1) the institutional dimension, (2) the personal dimension, and (3) the instructional dimension (Aronson \& Laughter, 2016; Richards, Brown, \& Forde, 2007). The institutional dimension emphasizes that need to reform various factors that affect the organization of schools, school policies, school funding and school resources (Aronson \& Laughter, 2016; Richards et al, 2007). The personal dimension refers to the process teachers learn to adopt more culturally responsive views and practices (Aronson \& Laughter, 2016; Richards et al, 2007). The instructional dimension refers to the practices of implementing cultural responsiveness into the classroom (Aronson \& Laughter, 2016; Richards et al, 2007). To implement this type of teaching requires a wide range of knowledge and experiences that allow for teachers to make curriculum and instruction for reflective and in response to diversity within the classroom. Some examples of adopting this type of practice includes adding real life experiences of diversity into teaching, incorporating all learning styles into instruction 
and assignments, being aware of their own biases, and providing access to varied practices, ideas, and ways of life (Levinson, 2009; OME, 2017).

This multicultural approach to education seeks to provide equitable learning opportunities for all students, despite the various racial, ethnic, social-class, or gender groups to which students belong (Bennett, 1995). This concept is an important aspect of not only education, but other fields such as medicine and social work (Davis et al., 2015).

In-risk students often exhibit many diverse characteristics and circumstances. While the overall dropout rate of Canada remains quite low, at only $9.5 \%$ in 2006 according to Statistics Canada, the number of students of specific groups who leave school early remains very high (Archambault, Janosz, Dupéré, Brault \& Andrew, 2017; Trypuc \& Heller, 2008). Attitudes towards diverse students can limit their success, further emphasizing how crucial it is for educators to develop an understanding of diversity amongst their students. From policy statements and school practices, it seems that agency schools are intended to assist students in continuing their education and resolve barriers that would otherwise potentially cause them to leave school early.

In a 2002 study on race and education, six high school teachers from downtown Toronto were interviewed to understand their experience teaching racial and ethnic minorities (James, 2002). In this study, educators often stereotyped minority students with labels, such as learning disabled, disruptive, problem students, and those more likely to drop out. This tendency is significant when discussing the transition back to community schools, wherein students often face stigma and unacceptance (Gronholm, Nye \& Michelson, 2018; Hughes \& Adera, 2006; The Learning Partnership, 2004). 
The issue of risk is important because educational attainment is linked to positive health, social, and economic outcomes in life (Javed, Javed \& Khan, 2016; Zimmerman, Woolf \& Haley, 2014). Ensuring that all students succeed within school and in the workforce is necessary for the future of our society and economy. However, despite the link between education and positive life outcomes, many students may be unable to succeed in school, and as a consequence these students are facing negative life outcomes such as leaving school early, getting involved in crime, joblessness, and negative health (Crocker, 2000; Javed, Javed \& Khan, 2016; Zimmerman, Woolf \& Haley, 2014).

It is an expectation that teachers are to care for the whole child (OME, 2009; Noddings, 2005), thus considering each child's academic, personal, social and emotional success and well-being (Swartz, 2017). Teaching the whole child is rooted in holistic education, which is an education philosophy where each individual is able to find meaning and purpose through the development of intellectual, emotional, social, physical and creative potential (Miller, 2016; Miller, 1990). Noddings (2005) further describes this approach to education as being an effective way to make our schools safer by building community and trust, "we must allow teachers and students to interact as whole persons, and we must develop policies that treat the school as a whole community" (p. 13). The concept of teaching to the whole child is relevant to my research, as a goal for agency schools is not merely to help students succeed academically, but also socially and emotionally (Ontario Centre of Excellence for Child and Youth Mental Health, 2012). One of my research questions sought to explore the types of skills being emphasized in agency schools by asking teachers, "What types of skills are you trying to teach these students?”. I am particularly interested in this topic, as students in agency schools often 
struggle not only with academic performance, but also with developing a healthy selfconcept and sustainable relationships with peers and educators (Ontario Centre of Excellence for Child and Youth Mental Health, 2012; OMCYS, 2015). For all students to achieve overall success, education must address the needs of all students. Students faced with various adversity may be placed in-risk of negative education outcomes if they are not provided with equal learning opportunities (Campie et al., 2015; OME 2009)

According to the OME (2017), multicultural education and culturally responsive practice are now widely implemented in schools across the province, and there are many different learning opportunities for educators around diverse and multicultural education such as conferences, workshops, and teacher education courses. On an anecdotal level, I have seen this shift in the practices being taught in my teacher education program, as well as the professional development training and policy documents released by the school board at which I work. There is an increase amongst cultural diversity, various types of families, and multiple gender identities that require a unique teaching approach that gives a voice to the diverse backgrounds that students are coming from today (OME, 2017; People for Education, 2018). To maintain the confidentiality with the school board used in this research, I did not assess the demographics of the agency schools involved. Although I do not specifically assess the demographics of the agency schools involved in this research, diversity in education is a very important topic to bring background to the realities of working with students in-risk. This movement towards multicultural education and culturally responsive practice will help shape education to be more inclusive, as well as combat risk factors that will help all students reach academic and overall success (OME, 2017). 


\section{Risk}

Risk is a collection of factors that increase an individual's vulnerability to negative health and development (Domitrovich, Durlak, Staley \& Weissberg, 2017; Hughes \& Adera, 2006). These may include individual, family, school, and community factors that may lead to consequences depending on a child's stage of development, as well as their level of resiliency to overcome these risks (Cabaj, McDonald \& Tough, 2014; Crocker, 2000; Domitrovich et al., 2017; Hughes \& Adera, 2006).

Individual factors include physical or mental health issues, disability, race, behavioural issues, substance misuse, learning difficulties, and negative social groups (Cabaj et al., 2014; Crocker, 2000; Domitrovich et al., 2017; Hughes \& Adera, 2006; The Learning Partnership, 2004). Family factors include low socioeconomic status, family stress, low parent education levels, lack of parental involvement in school, parental divorce, single-parent households, parental expectations, child abuse or neglect, and poor English language skills (Cabaj et al., 2014; Domitrovich et al., 2017). School factors include low academic standards, negative relationships with teachers or peers, unsupportive school culture, large enrollment and class sizes, low parent and community involvement, and lack of appropriate role models (Cabaj et al., 2014; Crocker, 2000; Domitrovich et al., 2017; Hughes \& Adera, 2006). Community factors include lack of community services, high levels of crime, unsafe neighborhoods, high unemployment, lack of adequate healthcare, and lack of affordable funding (Cabaj et al., 2014; Crocker, 2000; Domitrovich et al., 2017).

If students are unable to overcome these various risk factors, this may eventually lead the child to be considered at-risk of academic failure (Cabaj et al., 2014; 
Domitrovich, Durlak, Staley \& Weissberg, 2017; Hughes \& Adera, 2006). When understanding risk factors, risk accumulation is important to consider because greater exposure to risk will increase the likelihood of negative outcomes. Academic failure and leaving school early are a process that occur over time and result from a combination of individual, family, school, and community factors. The risk factors that are previously listed represent many types of diversity that teachers may encounter in their classroom. The studies mentioned above did not mention if or to what extent these risks are exasperated at the educational level when students transition out of agency schools. Many students experiencing these risks suffer from social isolation and bullying within the classroom (Acramidis, Bayliss \& Burden, 2000; Claymore, 2017). In this research, I sought to understand how the education system is attempting to reach each of these risk factors, for not only students, but for providing support to families as well.

\section{Resiliency}

For youth and adolescents to facilitate a healthy development and reach their full potential, they must be able to overcome the effects of being exposed to various risk factors and negative experiences (Masten, 2018; Rak \& Patterson, 1996). To adapt to the various challenges and stressors within the environment, youth need to develop resilience (Gardner \& Stephens-Pisecco, 2019; Masten, 2018; Williamson \& Witzel, 2016). Resilience is defined as "the capacity of those who are exposed to identifiable risk factors to overcome those risks and avoid negative outcomes such as delinquency and behavioural problems, psychological maladjustment, academic difficulties and physical complications" (Rak \& Patterson, 1996, p. 368). When individuals are resilient, they can 
cope with environmental stress and challenges in order to reach overall success (Gardner \& Stephens-Pisecco, 2019; Masten, 2011; Williamson \& Witzel, 2016).

Early work on resilience focuses on resilience that is occurring naturally, whereas more recent efforts have shifted towards ways to promote resilience (Masten, 2018). Emmy Werner and Ruth Smith conduced an influential study that began the shift from risk to resilience (Werner \& Smith, 1988). They conducted a longitudinal study that followed over 600 children born on the island of Kauai, Hawaii beginning at birth in 1955 and continuing over the next 32 years (Werner \& Smith, 1988). Werner and Smith (1988) found that there was a percentage of children who faced very adverse conditions such as chronic poverty, parents who had not graduated from high school, and family mental illness. Many of these children developed serious problems by the age of 10 , however, one-third of the children in those adverse situations still managed to do very well in their lives. Werner and Smith named these children "vulnerable, but invincible" (1988). The researchers checked in with their participants regularly over 32 years. It was noted that more of the high-risk children began to do better as they got older. Many of the individuals who experienced difficulties as teenagers (e.g. delinquencies, mental health problems, pregnancies), had become successful functioning adults (Werner \& Smith, 1988). Werner and Smith (1988) found that despite potentially debilitating risk factors, those who showed the most resiliency were those who developed what they described as protective factors. They noted that positive relationships, rather than risk factors seemed to have a more profound impact on the direction of an individual's life (Werner \& Smith, 1988). 
Efforts have moved away from a deficit-based model to a strength-based model, which focuses on understanding strengths, protective factors, and promoting competence and positive development (Gardner \& Stephens-Pisecco, 2019; Masten, 2018; Williamson \& Witzel, 2016). The most common factor for children who develop resiliency skills is at least one committed and stable relationship with a supportive parent, caregiver, or other adult (Gardner \& Stephens-Pisecco, 2019; Masten, 2018). Intervention for students in-risk requires adults to look for strengths, rather than weaknesses, and to be sensitive to a child's life experiences and difficulties (Gardner \& Stephens-Pisecco, 2019; Masten, 2018; Williamson \& Witzel, 2016). Strategies used to prevent and protect children within a resilience framework include efforts to reduce exposure to adversity, boost resources (e.g. food programs, health care), and mobilize protective processes and skills (e.g. improve quality of parent-child relationships, strengthen adaptive skills and self-regulatory capacities) (Masten, 2018).

It has been noted that agency schools have a large team of supports including educational assistants, social workers, teachers, and CYW's who work as part of a team to address the unique difficulties of children in their care (OMCYS, 2015). As part of my research, I was interested to understand how teachers prepare students to develop the right tools and resiliency skills to successfully transition back into community schools where class sizes are larger and fewer educational supports are available per classroom.

\section{Social Cognitive Theory}

Albert Bandura (1986) is the leading theorist in social cognitive theory (SCT), which emphasizes the importance of observing and modeling behaviours, attitudes, and emotional reactions of others. This theory was advanced by Bandura as an extension of 
his social learning theory (1977) in order to put greater emphasis on the cognitive components of observational learning and the way behaviour, cognition, and the environment interact to shape individuals (Bandura, 1986). Bandura believed that behavioural theories presuming that environment determines one's behaviour was too simplistic, and that the environment combined with one's behaviour actually causes the other (Bandura, 1977). Bandura (1977) explains that,

Learning would be exceedingly laborious, not to mention hazardous, if people had to rely solely on the effects of their own actions to inform them what to do. Fortunately, most human behavior is learned observationally through modeling: from observing others one forms an idea of how new behaviours are performed, and on later occasions this coded information serves as a guide for action. (p. 22)

People can make choices through self-reflection; however, the environment is a main influence on the way that people behave and learn (Bandura, 1986). SCT was developed after Bandura, along with colleagues, initiated a series of well-known studies on observational learning called the Bobo Doll experiments (Bandura, Ross \& Ross, 1961). These experiments examined the learning process modeled upon the adoption of aggressive behaviour in childhood (Bandura et al., 1961). Through a series of experiments, they watched children observe adults attacking Bobo Dolls, which are dolls that when hit, they would fall over and bounce back up again. When the children were allowed in the room with the dolls, they imitated the aggressive behaviour of the adults (Bandura et al., 1961). However, when they observed the adults acting aggressively and 
then being punished, Bandura noted that children were less willing to imitate the behaviour (Bandura et al., 1961).

SCT explains that people learn from one another through observation, imitation, and modeling (Bandura, 1986). Individuals that are observed are called models (Bandura, 1986). In society, children are surrounded by many influential models such as parents, family members, peers, and teachers. These models provide examples of behaviour to observe and imitate. Children pay attention to some of these models and encode their behaviour, a process involving the way individuals select and interpret the things going on around us (Bandura, 1986). At a later time, they may imitate the behaviour they have observed, whether the behaviour is positive or not (Bandura, 1986). The behaviour of the child will either be reinforced or punished by others around them, and this will likely determine whether or not the child will continue that behaviour (Bandura, 1986). Reinforcement can be internal or external, as well as it can be either positive or negative (Bandura, 1986). If a child wants approval from parents and peers, this is an external reinforcement, whereas feeling happy about being accepted is an internal reinforcement. A child will usually behave in a way that they believe will earn approval (Bandura, 1986).

The core concepts of the theory are explained by Bandura through what he described as a schematization of triadic reciprocal causation (Bandura, 1986). The schema shows that the reproduction of an observed behaviour is influenced by the interaction of three dimensions: personal, behavioural, and environmental (Bandura, 1986). The personal dimension relates to whether the individual has high or low selfefficacy towards the behaviour; the behavioural dimension is the response that an 
individual receives after they perform a behaviour; and the environmental dimension relates to the setting or environment that influences the individual's ability to successfully complete a behaviour (Bandura, 1986).

Self-efficacy is a major concept in Bandura's theory, which is described as a person's confidence in his or her ability to carry out a task (Bandura, 1986). Bandura's theory predicts that people will choose, persist, and put forth effort on tasks that they believe they can carry out successfully, as well as they will avoid situations they believe exceed their coping skills (Bandura, 1986). A good sense of self efficacy is believed to provide individuals with the resilience needed to overcome various risk factors and challenging situations (Bandura, 1986). SCT suggests that because personal, behavioural, and environmental factors have an impact on an individual's success, an intervention in a student's educational environment could influence their academic success (Bandura, 1986). Agency school programs could be thought of as an intervention because they target the risk factors and behaviour in a supportive environment that promotes selfefficacy. Positive role-models are crucial for students in-risk, as they can develop protective factors and resiliency skills from watching others around them. In this research, I strived to understand if teachers are able to reinforce positive behaviours and skills through modeling, while helping students develop self-efficacy.

\section{Social and Emotional Learning (SEL)}

For students to reach both academic and overall success and wellbeing, students must develop a set of skills and attitudes outside of the core curriculum (Taylor et al., 2017). Social and emotional learning (SEL) is defined as the process that individuals understand and manage emotions, set and achieve goals, feel and show empathy for 
others, make responsible decisions, and establish and maintain positive relationships (CASEL 2017; Greenberg, Dornitrovich, Weissberg \& Durlak, 2017; Swartz, 2017; Taylor et al., 2017). According to Swartz (2017), SEL is "key to important life outcomes, such as school and career success, because it fosters the ability of children to integrate thinking about their emotions and behaviours in ways that lead to positive academic and social outcomes" (p. 521). The field of SEL evolved from research on prevention and resilience (CASEL, 2017). According to CASEL (2017), there are five types of competencies related to SEL skills:

- Self-awareness: involves understanding one's own emotions, values, and behaviours (e.g. self-confidence, identify emotions, recognize strengths);

- Self-management: involves skills and attitudes that help to regulate one's behaviour and emotion according to different situations (e.g. stress management, self-motivation, goal setting, impulse control);

- Social awareness: involves understanding the perspective of others, including those with different backgrounds and cultures, while showing compassion and understanding social norms (e.g. empathy, respect for others, appreciate diversity);

- Relationship skills: involves maintaining healthy and rewarding relationships with others, as well as resisting negative social pressure and behaviours (e.g. communication, teamwork);

- Responsible decision making: involves knowledge and skills that will help make appropriate choices based on ethical standards, safety, consequences, 
and the health and wellbeing of those involved (e.g. identify problems, solve problems, reflect). (p. 2)

The skills and attitudes of each of these domains assist students in developing various short- and long-term goals. In the short-term, students can develop greater selfconfidence, greater attachment, greater empathy, fewer conduct problems, less emotional distress and risk taking and greater academic achievement (CASEL, 2017; Greenberg et al., 2017; Swartz, 2017). Follow up studies have shown that in the long-term, greater competence in SEL has made it more likely for students to be ready for post-secondary, succeed in their careers, have better mental health, and more positive relationships with family and friends (CASEL, 2017). Students who do not acquire these social and emotional skills are more likely to preform poorer academically and engage in negative behaviours, which can lead to students being placed at risk (Greenberg et al., 2017; Swartz, 2017).

Schools should help students improve their overall wellbeing, rather than just their academic skills (Greenberg et al., 2017). Society is now changing in ways where families are beginning to face greater economic pressures, schools are becoming increasingly multicultural, as well as children are now exposed to more complexities of the world through social media (Greenberg et al., 2017). These changes are beginning to emphasize the need for children to learn how to better manage stress, as well as get along with others in order to meet adult success (Greenberg et al., 2017; Swartz, 2017). SEL can be fostered in schools through approaches that promote students' capacity to integrate thinking, emotion, and behaviour to deal effectively with everyday challenges (Greenberg et al., 2017). 
Research is consistently showing that integrating SEL skills into education has positive effects (CASEL, 2011; CASEL, 2017). In 2011, CASEL and collaborating researchers conducted a meta-analysis of 213 studies that involved school-based social and emotional programs totaling 270,034 students from kindergarten to high school (Durlak et al, 2011). Most papers (75\%) were published in the last two decades (Durlak et al., 2011). This study showed that SEL programs improve mental health, social skills, and academic achievement (Durlak et al., 2011). Following this study, CASEL and collaborating researchers conducted another meta-analytic review of 82 different interventions of more recent studies involving more than 92,000 students from kindergarten to high school (2017). Most studies were conducted in the United States, and thirty-seven were from outside of the United States, indicating that SEL programs are being conducted around the world (Taylor at al., 2017). SEL outcomes were sorted into seven categories that included both positive and negative indicators of well-being: social and emotional skills; attitudes toward self, others and school; positive social behaviours; academic performance; conduct problems; emotional distress; and substance use. Social and emotional interventions in each classroom varied and follow-up was collected 6 months to 18 years post-intervention. This study found positive long-term effects of SEL programs across diverse age groups and demographics, including graduation rates among in-risk youth (Taylor at al., 2017).

Within agency schools, social and emotional learning is a large part of the daily learning goals (OMCYS, 2015). Students attending these treatment programs often lack these skills that help them cope with daily experiences and stressors, and so this is a large part of helping them in transitioning back into their community schools, as well as 
improving their overall wellbeing. In this research, I was interested to learn more about the skills being taught in order to reach these goals for students who may be facing various risk factors.

\section{The Role of Educators}

Teachers play an important role in helping students overcome risk in their life and reach their potential of academic and overall success. Positive teacher-student relationships will help students feel safe in their learning environment, which will support academic and social development (Brinkworth, Mcintyre, Juraschek \& Gehlbach, 2018; Newberry, 2010; Uitto, Lutovac, Jokikokko \& Kaasila, 2018). Students who have a secure relationship with their teachers have a secure base with the presence of warmth and positivity, which helps to develop self-esteem and self-concept (Hagenauer, Hascher, \& Volet, 2015; Murray \& Malmgren, 2005). Students who possess various risk factors especially benefit from positive teacher-student relationships. Creating positive relationships amongst students attending agency schools is especially crucial, as these students are in a very vulnerable situation (Hagenauer et al., 2015). There are many professionals working with students in-risk attending agency schools, and so a large part of creating a positive environment of effective treatment is through developing strong and supportive relationships.

An interdisciplinary team works together in an agency school to help students successfully transition back into their community school. This team generally consists of various professionals such as educators, CYWs, special education teachers, social workers, psychologists, child psychiatrists, nurses, family physicians, and various therapists (OMCYS, 2015). Work in these classrooms is focused on helping students 
develop the necessary skills required to cope with daily stressors and properly regulate behaviour (OMCYS, 2015). In this research, I sought to understand how teachers perceive their role and how the interdisciplinary team works together to help students.

Positive Relationships. Students can overcome difficulties when they are part of welcoming environments that place value on each student and hold a high expectation that they are able to succeed in life (Berkowitz, Moore, Astor \& Benbenishty, 2017). Many students facing risk factors do not have positive relationships or family support at home (OME, 2010), and so it is crucial that educators and support staff who are working with students in-risk build positive relationships and become positive role models to these students (Aronowitz, 2005; Rak \& Patterson, 1996).

Sanders et al. (2016), drew on data from a longitudinal investigation reporting on the role teachers play in building resilience and improving outcomes for youth experiencing various risk factors. Students reported on their experiences of teachers in educational settings (Sanders et. al., 2016). The experiences of two groups were analyzed, one facing high risks $(n=520)$ and the other facing low risk $(n=400)$. The youth explained that in order for them to learn and stay engaged in school, they need their teachers to understand them at an interpersonal level and be able to understand the challenges that they may be going through (Sanders et. al., 2016). According to Saunders et al. (2016), “when teachers build positive relationships with students that emphasize respect, and which are empowering of students, their resilience resources will be enhanced, and this also applies irrespective of levels of risk" (p. 119). This is consistent with other findings that explain how high-risk youth required interpersonal care to be a 
part of their relationship with their teacher in order to achieve academic success (Martin et. al., 2015).

The relationships that teachers build with their students can play a powerful role in mitigating the impact of risk that students may be facing (Martin et. al., 2015; Sanders et. al., 2016). In this research, I was interested to understand how teachers perceive their role working with students in-risk, and if they contribute student success and resilience to strong and supportive relationships with the teachers and agency staff.

\section{Social Capital Theory}

Social capital is a sociological concept which broadly refers to connections within and between social networks that can increase the likelihood of success in a purposive action (Bourdieu, 1983; Coleman, 1988). Though it is a widely used concept in a variety of contexts and disciplines, the core idea that social networks have value is shared (Acar, 2011; Dika \& Singh, 2002; Liou \& Chang, 2008). Generally, the term refers to (1) resources; (2) the relationships among these resources; and (3) the impact that these relationships have on the resources involved in each relationship, as well as the larger group (Acar, 2011; Dika \& Singh, 2002; Liou \& Chang, 2008). Early attempts to define social capital focused on the degree that social capital as a resource could be used for the

benefit of individual, group, or community. Although the term "social capital" originated as early as 1920, Bourdieu (1986) and Coleman (1988) are foundational to introducing the initial theoretical development of the concept (Dika \& Singh, 2002).

Bourdieu (1986) described social capital as a cluster of concepts, which include economic capital, social capital, and cultural capital, whereas Coleman (1988) focused on the role of social capital in the creation of human capital. Although both scholars focused 
on the roles that social capital had in the benefits for individuals or families through their relationships with others (Dika \& Singh, 2002), there are significant variations between the two.

Pierre Bourdieu (1986) proposes that the amount of social capital a person has, is dependent on the size of the network of connections they have, as well as the volume of capital possessed by each person to whom they are connected to. Therefore, his view of social capital is divided into two main elements: the social relationship that is allowing the individual resources to possess, as well as the quality and quantity of those resources (Dika \& Singh, 2002). Bourdieu (1986) describes capital as a cluster of concepts, which included economic capital, social capital, and cultural capital. Economic capital refers to money, property, and other assets; social capital refers to networks of support based on family, friends, or other individuals; and cultural capital refers to forms of knowledge, educational credentials, and skills (Bourdieu, 1986). These types of capital are very important as society includes various groups that have different amounts of economic, cultural, and social capital. Bourdieu (1986) looked to address the social inequity caused by levels of people's ownership over cultural capital. Privileged groups, such as groups of upper class, hold large amounts of economic capital resources such as greater access to social resources like information and knowledge (Liou \& Chang, 2008). When understanding Bourdieu's (1986) view of capital, these privileged groups aim to reproduce themselves, which means that those who are privileged will stay privileged, and those who fall outside of these groups will continue to be at a disadvantage.

James Coleman (1988) describes social capital as a resource that goes beyond individuals and includes relationships of trust and shared values in wider social networks. 
He defines social capital as, "a variety of entities with two elements in common: they all consist of some aspect of social structure, and they facilitate certain actors of actors whether persons or corporate actors - within the structure" (p.98). For Coleman, social capital is productive and defined by its function, which means that it is used in a way for individuals to achieve something that would have been impossible without it.

Research on the link between social capital and educational achievement emerged from both Bourdieu's (1986) and Coleman's (1988) theoretical approaches (Acar, 2001; Dika \& Singh, 2002). A major difference between Bourdieu and Coleman is that Bourdieu sees social capital as a tool of reproduction for the dominant class, whereas Coleman sees social capital as a positive way of social development (Dika \& Singh, 2002). Coleman emphasizes the idea that is up to the family to help advance their child's life chances, whereas Bourdieu emphasizes the idea that there are structural constraints and unequal access to resources based on class, gender, and race.

Coleman describes family and environment as the two main providers of social capital (Dika \& Singh, 2002). He argues that the expectations and norms within education that exist within the family and community are important social capital. These forms of social capital will influence factors such as parental involvement and investment, which turns into academic and overall success (Acar, 2011; Dika \& Singh, 2002). Variations in academic and overall student achievement can be attributed to parental expectations and involvement, connections between families and school, the overall climate of the school, and cultural norms and values in school and the community (Acar, 2011). 
Social capital is networks of shared norms and values that facilitate cooperation (Dika \& Singh, 2002). Family, friends, and community members frequently constitute as essential to individual well-being and success (Dika \& Singh, 2002). A wide range of research illustrates the way in which the use of various social connections may make a difference to individual well-being (Acar, 2011; Dika \& Singh, 2002; Liou \& Chang, 2008). Social capital theory provides a framework to this research. I sought to understand the types of social connections that are involved in helping a student reach success, as well as how teachers may be able to help increase a student's social capital despite risk factors.

Parent(s) and/or Guardian Support. The level of parental and/or guardian support in a child's education has been proven to be critical for a child's academic advancement and success (Haine-Schlagel \& Walsh, 2015; Simon 2001; OME, 2010; Van Voorhis, 2001). Coleman (1988) uses indicators such as family structure and parental support to measure social capital that affects education. He emphasizes the importance of factors such as higher parental educational expectations, parental monitoring, parent-child connections, and parents' involvement in their school as having a positive impact on educational outcomes (Dika \& Singh, 2002). When parent(s) and/or guardians are involved in a student's education, students have higher grades, school attendance, as well as graduation rates (Simon 2001; OME, 2010; Van Voorhis, 2001). Students may also experience higher self-esteem and self-efficacy, lower rates of aggression and violent behaviour, as well as overall well-being (Callahan, Pademacher, \& Hildreth, 1998; Henderson \& Mapp, 2002; OME, 2010).

The OME (2019) and OMCYS (2015) place a great deal of emphasis on ensuring 
that families have a critical role in supporting children and youth in community and agency school programs. Parent(s) and/or guardians are required to be involved in the treatment process of students attending CTCC programs, where they are attending scheduled meetings and being involved in social work services. OMCYS (2015) states that family capacity building is a service provided that seeks to promote the resilience of the family, as well as enhance the overall function of the family to support children and youth with mental health problems. Support may involve changing one's parenting behaviour at home, continuing intervention delivery at home, as well as supporting the child's behaviour changes (Haine-Schlagel \& Walsh, 2015).

Research by Brown and Beckett (2007) explain how crucial it is for parent(s) and/or guardians to be involved in the education of students facing various risk factors. However, they found that some alternative schools themselves that do not encourage outside involvement from classroom teachers or parents. They explain that it is typical that regular school teachers have little to no contact with alternative schools, and the parent's only involvement is to attend entrance and exit meetings (Brown \& Beckett, 2007). According to Brown and Beckett (2007),

Nowhere is the challenge of improving communication between parents and teachers greater than in schools that are resented by parents as stigmatizing children and isolating them from mainstream educational opportunities, and which charge teachers with the task of returning students as quickly as possible. (Brown \& Beckett, 2007, p. 499)

These findings were motivation for me to understand if agency school teachers and staff are promoting and supporting family involvement in their programs. Some 
research around students facing risk factors, as well as students receiving mental health treatment, demonstrate that parental support in mental health treatment is lacking (BakerEriczen et al. 2013; Haine-Schlagel et al. 2011). Parents may face challenges to participate actively in treatment such as by feeling blamed, judged, and not listened to by professionals, as well as feeling dissatisfied with their child's education and mental health services in general (Baker-Ericzen et al. 2013). Support can also be influenced by various factors such as parent education level, language, socioeconomic status, cultural influences, and attitudes of school staff. Obstacles such as work, and transportation may also operate as barriers for parents to participate in their child's education (HaineSchlagel \& Walsh, 2015). According to Murray et al. (2014),

there is evidence that some teachers may not invite parent involvement because of their frustration with low-achieving, low SES students (Eccles \& Harold, 1993; Van Velsor \& Orozco, 2007) or because they view the family as the source of their students' achievement problems. (p. 4)

Blaming the student or the parent for their lack of support places educators in a position of superiority, and thus results in a lack of strategies that could address the obstacles being faced by families facing various risk factors.

In this study, I specifically aimed to understand what is currently in place within agency schools to promote parent(s) and/or guardian support, and what strategies are being utilized to overcome barriers for those who are otherwise eager to become involved, but cannot due to work obligations and financial limitations. 


\section{The Role of Schools}

Schools play a critical role in ensuring that all students can achieve success, regardless of various risk factors. Although schools are unable to solve all the problems that students may be faced with, they play a large role in ensuring educational success. Creating a positive school environment that promotes success for all students is vital in creating an inclusive and supportive environment.

Agency Schools. CTCC programs provide critical support to meet the needs of children and youth who cannot attend community school due to their need for care, treatment, or rehabilitation services (OME, 2019). My literature review revealed a large variety of CTCC programs labeled as 'day treatment', 'alternative' or 'agency' schooling across the province. Although labels may vary, these programs operate under CTCC guidelines (2019) and the OME has identified three essential elements for these programs: (1) instruction and intervention; (2) assessment, evaluation and reporting on educational achievement; and (3) transition planning. A list of the guidelines included in each of these elements can be found on p. 7 - p. 11 of the OME Guidelines for Approval of Provision of CTCC Programs (2019). According to the OME (2019), these elements "provide the conditions to improve achievement; reduce gaps in achievement; and to increase public confidence in the publicly funded education system” (p. 7).

All classroom programs offer an academic program that is administered by the special education teachers, as well as various types of mental health services administered by social workers, psychologists, and CYWs, such as targeted prevention, counseling and therapy, family support, crisis support services, and life and social skills training (OMCYS, 2015). The primary academic focus of agency schools is on literacy 
and numeracy skills (OME, 2009). Typically, there is maximum of eight youths per classroom, with a teacher and one or two CYWs assigned to each classroom at all times (OMCYS, 2015). In Ontario schools, the education program is based on Ontario Curriculum, however instruction delivery is differentiated based on individual student needs and strengths (OME, 2019).

The shared goal of this interdisciplinary team is to help students attending these programs develop the knowledge, skills, and attitudes that will help them successfully transition back into their community school. Students are following an individualized approach to the OME curriculum guidelines to meet their specific learning needs. (OME, 2019).

Through this research, I explored the understandings of the educators involved in the types of programs offered at agency schools, specifically in Southwestern Ontario. Understanding the way in which agency schools operate was highly important for the research being conducted. The intention is that this knowledge will assist in bridging gaps in support and success for students in-risk as they transition back into community school settings.

Successful Transition. Transition planning prepares children, youth, and their families for the transition back to community school, to other community supports, to adult mental health services, or for discharge from services (OMCYS, 2015; OME, 2019). School board and agency staff must facilitate effective transitions where students receive continuous services and resources when being admitted and demitted from agency school programs (OMCYS, 2015; OME, 2019). When developing transition plans, multidisciplinary teams of individuals such as parents/guardians, educators, 
community partners, and professional agencies create and develop plans based on students' strengths and needs to create a seamless transition to and from agency schools (OMCYS, 2015; OME, 2019). Planning is completed by setting clear goals for treatment, as well as ongoing analysis in order to track student progress and adjust when necessary (OMCYS, 2015; OME, 2019). During this process, teachers from community schools will have access to student education plans and will attend transition meetings with agency school staff to assist with this transition, as well as planning and delivery in community school classrooms (OME, 2009; OME 2019). Along with a transition plan, education plans for these students include an Individualized Education Plan (IEP), a Behaviour Support Plan (BSP), or a Safety Plan. Students will often have these plans prior to attending agency schools, which are intended to remedy undesired behaviour and academic achievement (OME, 2010).

The goal of treatment planning and preparation is to result in minimal disruption to treatment gains (OMCYS, 2015; OME, 2019). Following discharge, follow up contact is considered best practice and contact should be completed within three to six months (OMCYS, 2015). During this time, the child is assessed to understand if additional supports and services for the student are necessary. If the child or youth reports or displays deteriorated functioning, it will be determined whether or not the student's plan will be revisited and what services should be recommended (OMCYS, 2015; OME, 2019). In some cases, when appropriate, the child or youth may re-enter treatment services (OMCYS, 2015; OME, 2019).

When students move back into community schools, they are adjusting to new levels of support, adjusted curriculum, and larger class sizes. Students in-risk require 
support during this transition period, as well as when they are fully integrated back into community schools to reach success. In this research, I specifically desired to understand what constitutes as a successful student transition, as well as how teachers are able to help students prepare for this significant adjustment back into community school settings. 


\section{CHAPTER 3}

\section{METHODOLOGY}

In this research study, I focused on the perspectives of teachers that are working with students in-risk who are receiving treatment in agency schools. I used an exploratory approach to investigate the lived experiences of participants. A qualitative research design served to be the most beneficial design for this study. Qualitative methodologies use a descriptive approach to understand people and events studied by focusing on inquiry, as well as understanding how the participants interpret their lived experiences (Creswell, 2007). I investigated the lived experiences of teachers working in agency schools in a Southwestern Ontario school board. This is a collective case study where multiple cases are selected (Creswell, 2007). I used the Interpretive Phenomenological Analysis (IPA), which is an approach to qualitative research that involves a detailed examination of a participant's life, to understand a given phenomenon (Finlay, 2011; Piekiewicz \& Smith, 2014; Smith \& Osborn, 2007).

Table 1

Summary of Research Framework for this Study

\begin{tabular}{|l|l|}
\hline Philosophy & Phenomenological \\
\hline Ontology & Social Constructionism \\
\hline Epistemology & Interpretive (hermeneutics) \\
\hline Methodology & Qualitative \\
\hline Approach & Inductive \\
\hline Research Design & Mono-perspectival study (perspective of teachers) \\
\hline Method & Semi-structured in-depth interviews \\
\hline
\end{tabular}




\section{Interpretive Phenomenological Analysis}

IPA is an investigative and experiential approach concerned with making meaning of a certain experience to a given participant and recognizing its significance for that participant. IPA is an inductive approach that does not test hypothesis and avoids prior assumptions (Reid, Flowers \& Larking, 2005). IPA was developed by Smith (1996) and combines the principles of phenomenology, hermeneutics, and ideography (Smith \& Osborn, 2007).

Phenomenology is a philosophical approach to the study of experience.

Phenomenological inquiry has two different approaches: descriptive phenomenology and interpretive phenomenology. Descriptive phenomenology aims to describe a lived experience without attempting to give meaning to it (Smith et al., 2009). Edmund Husserl (1927) was the first to develop descriptive phenomenology and suggests that during data collection and analysis, the researcher should leave aside their previous knowledge in order to see phenomena as experienced. Husserl's main influence in IPA is through the process of going back and reflecting on the phenomena, rather than attempting to address the experience. Interpretive phenomenology aims to reveal and interpret the embedded meaning in a lived experience. Martin Heidegger (1962) a student of Husserl, built upon these ideas by questioning the possibility of the lived world without that of an interpretative lens (Heidegger, 1962). He suggested that knowledge of the lived world can only happen through interpretation of people, relationships, and language. To recognize essential components of experience, phenomenological studies will look to how individuals talk about objects and events by focusing on understanding the human experience from the perspective of those who lived the phenomenon. This is carried out 
by encouraging them to express their experiences freely and highly credits them to their actions and reflection having significant meaning and purpose (Piekiewicz \& Smith, 2014; Smith \& Osborn, 2007).

The next major theoretical foundation of IPA is hermeneutics. Hermeneutics is defined as the theory and practice of the interpretation of the meaning of text (Smith et al., 2009; Tuffour, 2017). According to hermeneutics, to fully understand an experience, you must be able to understand an individual's language and mind-set (Piekiewicz \& Smith, 2014). Researchers who apply the IPA approach draw on the perspectives of hermeneutic theorists such as Schleiermacher and Heidegger (Piekiewicz \& Smith; Tuffour, 2017). Schleiermacher was interested in interpreting biblical texts in a way that would not only revel meaning, but also (un)intentional motivations of the original author (Schleiermacher, 1998; Tuffour, 2017). His interpretative perspective of understanding used a grammatical and psychological dual stance, where he would bring together the understanding of both the context of a text, as well as the understanding of the author (Schleiermacher, 1998). Building upon this, Heidegger explained that human existence is bound to the world of people, language, relationships, and culture (Heidegger, 1962). Therefore, in order to understand any phenomenon of lived experience you must be able to interpret the mind-set of an individual's experience.

The final theoretical foundation of IPA is ideography. Ideography is concentrated on examining the detailed experience prior to moving to more general claims, which focus on specific experience, rather than general experience (Piekiewicz \& Smith, 2014). IPA focuses on analyzing a small number of cases to create meaningful understanding about narrow focus of participant experience (Smith et al., 2009). The main approach to 
ideography is to explore each individual case before moving to the general cross-case analysis of convergence and divergence between cases. When analyzing the data, researchers are required to follow this approach by taking careful examination of the convergence and divergence between participants' experiences.

IPA is particularly used to understand under-examined phenomena, novel phenomena, or phenomena that is difficult to explain (Piekiewicz \& Smith, 2014). For this purpose, a lived-experience used to make meaning can provide a very detailed understanding of a certain situation, as well as open other areas of exploration. IPA is a methodology that is frequently used in qualitative research with a small sample size and interviews (Piekiewicz \& Smith, 2014). Applying IPA helped me explore and interpret the perspectives of the participants, as well as better understand the functioning of these programs and transitions. Moreover, this exploratory approach provides preliminary evidence that can be used in further research studies.

\section{Positive Psychology}

In this study, I specifically chose to focus on a strengths-based approach when understanding the experiences of teachers working in agency schools. Positive psychology is an approach to studying human thoughts and behaviour, with a focus on strengths instead of weakness (Heffernon \& Boniwell, 2011; Sheldon \& King, 2001). I am particularly interested in the achievements of agency schools, as well as how students are able to successfully transition back into a community school setting.

In psychology, focusing on the positive is more of a millennial phenomenon. Seligman is regarded as the person responsible for the creation of the positive psychology movement (Heffernon \& Boniwell, 2011). He wanted to move pathologically focused 
psychology towards studying strength and building what works and what is improving (Heffernon \& Boniwell, 2011; Sheldon \& King, 2001). Focusing on a negative bias or a deficit may limit understanding of typical and successful human functioning (Sheldon \& King, 2001). Seligman and Csikszemtmihalyi's foundational paper of this new field was published in 2000, which provoked a new focus on positive phenomena and establishing a base for the application of positive principals (Heffernon \& Boniwell, 2011). Using a strengths-based approach will give a new perspective on existing ideas, as well as will look to how individuals and groups thrive in order to increase the wellbeing of one another. To gain further insight into the experiences of agency school teachers, IPA is used to capture and explore the meanings of their individual experience. Reid, Flowers, and Larking (2005) suggest that there is space for IPA studies to focus on positive experiences:

In keeping with the broad premise of positive psychology (e.g. Seligman \& Csikszentmihalyi, 2000), there is scope for IPA research to become less disease and deficit-focused, and for participants to be given a chance to express their views about strength, wellness, and quality of life. (p.21)

The questioning in this study was open-ended, and so participants were able to interpret the questions and answer in a way that was meaningful to them. Participants naturally focused on the strengths of the programs, while constructively including areas that could be improved. I began this research project in order to discover and capture the lived experience of agency school teachers through IPA. 


\section{Selection Criteria and Recruitment}

For this purpose of this study, I was only interested in the perspectives of teachers currently working in agency school settings for at least 2 years. It was believed that these teachers would be confident in their roles and have unique experiences and perspectives to share working with students with various risk factors.

Before participant recruitment began, approval was obtained from the Research Ethics Board (REB) at the University of Windsor (see Appendix C), as well as approval from the school board used in this study. Once I received both approvals, the school board sent out a recruitment email (see Appendix D) in March 2019 to all teachers working in agency school settings. The email included information indicating the nature of the study, my contact information, and the letter of consent (see Appendix E). Teachers were given two weeks to decide if they were interested in being interviewed for this study. Willing participants responded to my contact information included on the email and I replied by sending an email verifying participant's commitment, followed by a phone call to arrange a meeting time and location that was convenient for the participant. Reminder recruitment emails would have been sent out, however this was not necessary as I received a high response rate to the initial email. I used the first seven participants that responded to the recruitment email. Participants received a $\$ 20.00$ gift card as compensation for taking the time to complete the interview process. This compensation was paid for by myself as the researcher and was approved by both the University of Windsor REB, as well as the school board prior to conducting this study.

Volunteers were confident in their experiences and understanding of the programs and resources they offer because individuals who agreed to participate are more likely to 
understand the validity and relevance of the study than those who refused to participate (Creswell, 2007). In this study, all participants were from one school board from a region in Southwestern Ontario, all were female, and all teachers had a minimum of two years' experience teaching in an agency school setting. The participant's involvement in the study was voluntary, and participants were very willing to talk in-depth about their experience as a teacher in an agency school.

\section{Research Design}

I explored the lived experiences of teachers who are currently working in agency school settings in a region in Southwestern Ontario. The study is based on semistructured interviews of seven teachers from elementary and secondary agency schools in a Southwestern Ontario school board. Semi-structured interviews resonate with the IPA model, which emphasizes discovering the meaning of various phenomena from the experience and perspective of the participant (Piekiewicz \& Smith, 2014; Smith \& Osborn, 2007). Seven participants were interviewed, and the perspectives of the participant group has an impact on the in-depth analysis of agency schools. IPA emphasizes that a small sample size will provide a more meaningful analysis in understanding novel circumstances (Finlay, 2011; Piekiewicz \& Smith, 2014; Smith \& Osborn, 2007).

The interviews were coded so that I was able to recognize common themes and allow for an interpretative analysis of the data (Creswell, 2007). Using this design, I offer insight into how teachers perceive their roles in alternative school settings, and how their role affects the overall achievement of students in-risk. This study differs from an action research study because I am not trying to find a solution to a given problem, but 
rather I am trying to further understand the perspectives of teachers based on descriptive and exploratory factors, in hopes of better understanding these programs.

\section{Data Collection}

Data was gathered from participants during one semi-structured interview (see Appendix B for guiding questions). When scheduling the interviews, it was important to find a location and environment that was both safe and comfortable to the participant. Interview dates were scheduled and arranged at the convenience of the participants. All interviews were conducted in either a private space in the participants' school, or a private study room in a library near the participants' school. These were the most convenient locations for the participants in this study.

At the start of each interview, participants were asked to once again review and sign the consent form (see Appendix E). Participants were given time to ask any additional questions, and then the purpose of the study was restated before the interview began. Interviews were semi-structured, and on average, the total time for each interview was approximately 45 minutes.

Interview questions were designed to gain perspectives on the roles of teachers who are working in agency school settings. The questions were used as a guide to facilitate reflection and deeper level thinking. I used a non-directive style of interviewing using open-ended questioning to allow participants to control the pace and subject matter of the interview. Open-ended questions are questions that can be answered in depth and allow for unique responses without being limited to one-word answers. Evidence was gathered using open-ended questions to encourage a meaningful dialogue that captured the experiences of the individuals. According to Creswell (2007), "the more open-ended 
the questioning, the better, as the researcher listens carefully to what people say or do in their life setting" (p. 21). When clarification of information was needed, I used a more directive style of questioning.

The primary concern of IPA researchers is to take detailed accounts of the experience of participants in order to understand the phenomena at hand (Finlay, 2011; Piekiewicz \& Smith, 2014; Smith \& Osborn, 2007). For this reason, audio recording was used during the interview to ensure that data is accurate during the transcription phase. I also took notes during the interview to be sure that I was able to get an accurate representation of not only the participants answers, but their body language and emotions as well. A recording device was used. Files were deleted off the recording device and exported onto a USB by file number after the interviews were completed. Participants' names and schools are be disclosed in this manuscript, and taping was kept confidential and secured in a locked cabinet. Participants were aware of this prior to giving full consent to participating in research. The interviews were a voluntary procedure and participants were free to withdraw responses at any point prior to the data analysis. At that point, all data contribution remained in the study. There was no consequence if participants decided to withdraw from the study. The destruction of the audio tapes was completed after transcription and verification.

During the interview, it was crucial that as the researcher I was asking open-ended questions, as well as that I was able to build a rapport and build trust with my participants (Esterberg, 2002). I did this by trying to make the interviewee as comfortable as possible, as well as monitoring the participants' emotions to be sure that they were not speaking about certain issues that made them uncomfortable or bring up negative emotions 
(Esterberg, 2002). Participants were fully aware that they were able to skip any question during the interview process.

\section{Participants}

All participants were teachers working in an agency school setting for a school board in a region in Southwestern Ontario. Agency schools at the elementary level, as well as agency schools at the high school level were both used for this study. The two major differences between the types of schools involved in this study was the age and level of treatment, as well as the types of transition teams. At the secondary level, there was a transition team that included two transition teachers, and one transition CYW. Whereas at the elementary level, the student transitions fell under the responsibility of the homeroom teacher and CYW.

Seven teachers participated in this research study. In order to maintain confidentiality and anonymity pseudonyms have been used, as well as the omission of other identifiable information such as school board and school information, specific lengths of service, and grades being taught.

Participant A: Sara. Sara has been working as an agency school teacher for under five years. She works at an elementary school that teaches students up to 12 years of age.

Participant B: Jane. Jane has been working as an agency school teacher for over 15 years. She works at an elementary school that teaches students up to 12 years of age.

Participant $\boldsymbol{C}$ : Mia. Mia has been working as an agency school teacher for over 15 years. She works at a secondary school for students 13 years and older.

Participant D: Vanessa. Vanessa has been working as an agency school teacher for over 10 years. She works at a secondary school for students 13 years and older. 
Participant E: Patricia. Patricia has been working as an agency school teacher for 10 years. She works at a secondary school for students 13 years and older.

Participant F: Heather. Heather has been working as an agency school teacher for 20 years. She works at a secondary school for students 13 years and older.

Participant G: Laura. Laura has been working in an agency school for over 5 years. She works at a secondary school for students 13 years and older.

Student Challenges. These agency school teachers described the students attending their programs as having many diverse challenges. They are placed into day treatment programming ultimately because they are not able to function in their community school for a number of reasons. Typically, students face severe mental health challenges that are coupled with behavioural and learning needs. A number of other risk factors including family challenges, poverty, bullying, and trauma were also described as being quite common. Many youth face extreme difficulties with self-regulation and coping because of these challenges. Self-regulation refers to the ability to control your behaviour and emotions in a way that is socially appropriate and in accordance with the demands of the situation (Miller et al., 2018).

\section{IPA Analysis}

IPA analysis is an analytic process that encourages researchers to use their theoretical knowledge to inductively analyze data (Smith et al., 2009). IPA analysis differs from other qualitative approaches in that it focuses on the participants' process of making sense of their experiences, as much as it does on the experiences themselves. Although there is no single method of data analysis for IPA, I have used the steps suggested by Smith et al. (2009) to guide me in analyzing the data as a novice researcher. 
Analyzing the data after the interviews were completed involved a six-step approach (see Table 2).

Table 2

Steps for analysis in Interpretive Phenomenological Analysis (Smith et al., 2009 p. 82107).

Step 1: Reading and re-reading

Step 2: Exploratory commenting

Step 3: Developing emergent themes

Step 4: Searching for connections across emergent themes

Step 5: Moving to the next case

Step 6: Looking for patterns across cases

Individual Case Analysis. Step one involved a close examination of each transcript. This initial stage of data analysis involved immersing myself in the data in order to get a better account of what the participants are experiencing. While reading each transcript, I listened to the audio recording again to really hear the experiences shared. Step two involved initial noting to examine the content on a very exploratory level. During this stage, I documented the topics that seemed important and tried to capture the meaning of these topics. The comments were divided into three areas: descriptive comments, which focus on focus on content and describe the object of concern; linguistic comments, which reflect on the specific use of language; and conceptual comments, which ask questions of the data and move towards a more conceptual understanding of what the dialogue means in this context (Smith et al., 2009). 
According to Pietkiewicz \& Smith (2014) "each reading and listening to the recording may provide new insights" (p.12). During this process, I made notes about my reflections and observations of the experience that I believed to be significant to the research and emerging themes. My experiences as a teacher were able to assist me in interpreting participants experiences because I was able to compare some of the phenomenon of interest to my work teaching in community schools.

Emergent Themes. Step three focused on creating chunks of text in order to understand what was learned through exploratory commenting. Emergent themes were developed to capture the understanding. Step four introduced structure into the analysis. Emergent themes were drawn together by identifying similarities between them, as well as looking for frequency of use during the interview. During step five, I began to analyze the remaining transcripts using stages one to four. Each case was approached individually to allow new themes to develop.

Cross Case Analysis. The final stage involved searching for connections across cases. Through this process, themes were labelled, reconfigured, and discarded if they were not recurrent across cases. In the final analysis of the data, I developed a narrative account of the study that involved both the participants' account of their experiences in their own words, as well as my interpretive understanding. This is followed by the final chapter, which includes a discussion identifying each theme, as well as reflection on initial research questions, implications and limitations of the study, and ideas for future research. 


\section{Ethical Considerations}

There were many important ethical considerations made during the recruitment of participants, data collection, and data analysis. The research proposal received approval from the University of Windsor's REB, as well as was conducted using the principals stated in the Tri-Council Policy Statement: Ethical Conduct of Research Involving Humans. Approval to conduct research was also granted by the school board involved. All potential research participants voluntarily participated in the research. Once both institutions granted approval, principals sent out a participant recruitment email explaining the nature of the study.

On the day of the interview, participants received a detailed consent form to review and sign. The consent form provided detail on the purpose of the study, procedures, potential risk, compensation, and protection of identity. In order to protect the identity of the participants and their schools, pseudonyms were used throughout this paper to keep confidentiality and anonymity. Although identities will be kept confidential, because of the nature of the study using a very small sample size, readers familiar with the city and school board used in Southwestern Ontario may be able to recognize the school or participants involved in the research. Participants were aware of this possibility prior to giving consent to participate. In order to minimize this possibility, I tried to only include information that would not easily identify the school or participants used, as well as kept participant descriptions brief.

There was no intention on the part of the investigator to include any psychological or social risk to the participant. Participants had the right to withdraw from the study at any time prior to analyzing the data. Participants had the choice to refrain from answering 
any questions in the interview. Lastly, all participants had the chance to review interview transcriptions for up to two weeks after it was sent to them. All seven participants reviewed their transcript and were able to many minor changes to ensure that their perceptions were accurately analyzed. Confirmation from the participants was needed to ensure that they reviewed their transcript prior to data analysis. Each participant sent email confirmation that they reviewed their transcript, as well as whether or not they made minor changes. The research study was reviewed to ensure that it respects the dignity and privacy of all participants.

\section{Limitations and Delimitations}

The primary limitation of the study was the generalizability of findings. This study consisted of only seven teachers from one school board in a region in Southwestern Ontario. Each school is a unique system, and so the results of the study cannot be generalized to other settings or schools. With only seven participants, there is no way that the experiences of the teachers in this study represent the experiences and attitudes of the teachers of Ontario. It should also be understood that any variations in participants' experiences would have resulted in a different interpretation of the data, and as a result, themes and recommendations may have been different. Therefore, the findings should be interpreted with caution and not be generalized beyond the experiences of these seven individuals. However, this research did not seek to generalize, but rather to explore the subtle nuances and reflections on the lived experiences of teachers working in agency schools. To enhance the transferability of this research, further research studies should be conducted that employ a more diverse sample of special education teachers working in alternative school settings. 
Another limitation of this study may be social desirability. Participants may have responded to the interview questions based on perceived social or political correctness, rather than based on their true attitudes and experiences towards agency schools and the resources and strategies currently in place.

A delimitation to this study is that it did not take place in a large number of school boards. Various factors such as size, population, location, staff, and school culture may have an effect on the results of the types of programs and strategies that work for success of the students. Although the results of this study may explain resources and strategies only useful for the specific schools involved, this study looked to understand individual reflections that may be useful for future research. 


\section{CHAPTER 4}

\section{DATA ANALYSIS}

In conducting this study, I have aimed to present and interpret the perspective of teachers to develop a deeper understanding of the structure and dynamics of day treatment programs and transitions. In this chapter the narratives that were shared by each participant during their interviews are presented through participant excerpts and interpretive commentary. Each teacher shared unique and meaningful perspectives on agency schools and student transitions. The seven attitudes toward agency schools and student transitions should not be generalized or considered to represent the attitudes and practices of teachers across Ontario. However, this study may give important information and insight to help support the current practice of teachers in similar circumstances. The experiences that these seven participants shared have generated further questions about this research field.

To begin the semi-structured interview, all participants were asked preliminary questions using positive psychological strategies that were intended to give me background information about the participant and what they do, as well as to help make the participant feel more comfortable. These preliminary questions included, "How long have you been a teacher in an agency school setting?", "How would you describe this role?", and "What types of challenges are these students faced with?". During this time, teachers spoke in detail about their schools and the services offered, how long they have been teaching in agency schools, the various roles they may have taken on over the years, as well as the diverse types of challenges students are facing. It was fascinating to hear the diverse set of experiences each participant had. Teachers taught different ages, had 
various types of student needs, and years of teaching experience in an agency school that ranged from three to twenty years. Each participant had something very valuable to bring to this research. In order to gain insight into teachers' perceptions and experiences working in agency school settings, the guiding questions for the semi-structured interviews focused on obtaining information about: (1) teachers' role; (2) student challenges and risk factors; (3) intervention programs; and (4) student transitions.

The following themes were drawn from applying IPA analysis: 1) Teaching the Whole Child; 2) Communication; 3) Collaboration and Team Dynamics; 4) The Present Role of Parent(s) and/or Guardians; and 5) Successful and Adaptive Transition. These themes will be discussed in detail through participant excerpts, interpretative commentary, as well as further discussion including the guiding questions used in the semi-structured interview.

\section{Theme 1: Teaching the Whole Child}

Teaching the whole child is an approach to teaching that does not merely consider a students' academic success, but their personal, social, and emotional success as well (OME, 2009; Swartz, 2017). When students are placed in an agency school setting, they have a variety of challenges they may be facing which can affect not only their academic success, but their social and emotional health and well-being. It was clear from the interviews that day treatment programs place a very large emphasis on teaching the whole child and focusing on SEL to teach coping skills and strategies. Academics is still a part of their day; however, they are only required to cover parts of the literacy and mathematics curriculum (OME, 2009). When teachers were asked about their role and 
what a typical day looked like, they spoke heavily about the intervention programs and SEL teaching strategies used on a daily basis.

Many teachers explained that student treatment comes before academics. Laura stated that, "if we don't have the mental health piece, academics take a back seat". Jane agreed by explaining that being a treatment center often comes first,

First, we're a treatment center, and then the academics. So that's why we only focus on numeracy and literacy. Because when we're focusing on their behaviours and social skills, and just their mental health, there is not enough time to do all of the subjects in a regular school. And if the child is in crisis, why am I teaching them math?

Students are placed in these settings because they are unable to function in a regular school setting. Students may be experiencing serious mental health problems such as suicidal thoughts, anxiety, or panic attacks that make it hard to be in any social situation. Others may be facing behavioural issues such as extreme aggression or violence. When you begin to understand what these challenges look like, it becomes very clear why academics becomes secondary importance during intervention. Some participants explained that this is a large shift for many teachers. Emphasis on curriculum is a large focus for community school teachers. This is likely a factor that makes it so difficult for these students to function in a community school setting if their risk factors and challenges are not mitigated. Jane explained how her perception of teaching and accomplishment had to initially shift when she first started teaching in agency schools, Some teachers just want to teach. And when I first started teaching, I would bring this to a teacher who still teaches there now, but she has a few more years than 
me. And I would say, you know, I feel like I didn't do any teaching today. And as a teacher, that's really hard to swallow because you want to teach. But she would say, well what did you do? Did all the kids stay in the classroom? Yes. Was everybody safe? Were there any fights? Swearing? We have to break it down to what you actually did accomplish that day. Sometimes we have students who haven't been in a classroom for months. We've had students whose parents had to take them out of school because they couldn't be in a classroom. So now because I have been teaching in it for so long, I can pull back when I have to. Or I can bring on the academics if they're like the class I have now who are so willing to learn.

I believe that there are many community school teachers who may also feel this way. It is very easy to have the same types of reservations as Jane because teachers can be constantly pushed to believe that the focus should be placed mainly on academic success. However, accomplishment does not solely come from what a child can achieve academically. I believe that this is something that both teachers and students need to shift to understand. Jane also explained the diverse challenges that students may be faced with. I believe that what she was explaining does not only focus on increasing their social and emotional health, but also on building strong student-teacher relationships in order to really understand and support students. According to Saunders et. al (2016), in order for youth to learn and stay engaged in school, they need their teachers to understand them at an interpersonal level and be able to understand the challenges that they may be going through. Jane also spoke of many relevant challenges for all teachers. With the diversity of classrooms changing (People for Education, 2018; OME, 2017), many teachers are 
faced with a classroom of complex needs. Teachers need to be able to reflect on their practices and see that some days may be much more challenging than others, some days may be spent heavily on emphasising team work and collaboration in their classroom rather than heavily on academics; however, there will still be success in each day.

Teachers were asked a variety of questions that for many of them lead to a detailed description of SEL. These questions included, "What supports do you provide for the students", "What does a typical day look like for these students?", "How does it differ from the average community school day?" and "What types of skills are you trying to teach these students". The literature described how we are able to help students develop resiliency skills that will help them overcome risk factors (Gardner \& StephensPisecco, 2019; Masten, 2018; Williamson \& Witzel, 2016). Many times, the behaviour that a student possesses is a product of what they have learned from others around them. Having a positive role-model who is able to promote the proper skills and tools in order to help them develop protective factors and resiliency skills is a concept that comes from Bandura et al. (1961). Heather explained how they help students develop self-regulation skills in order to cope with various emotions,

I would say self-regulation skills are a key. Whether it be an overwhelming sense of anxiety, or a sense of angry frustration. Whatever the emotion, the regulation and the ability to cope with those emotions and how that looks... those skills are being developed all the time. A few programs we use throughout the school is the beaker program, the decider program, which is another program that introduces a variety of skills related to interpersonal effectiveness, mindfulness, distress tolerance, and self-regulation. So those are all being developed within their team. 
So social workers, teachers, CYWs would focus on those, it's a part of the language within the schools.

Self-regulation includes the ability to resist highly emotional reactions to upsetting stimuli, to calm yourself down when you are upset, to handle frustration, as well as to adjust to change (Miller et al., 2018). It is a set of skills that enables children to be able to work towards a goal, despite the unpredictability of our feelings and the world around us. Problems with self-regulation manifest in different ways depending on the child (Miller et al., 2018). Some children may have instantaneous strong reactions, where other children may build up distress which eventually leads to a behavioural outburst. Regardless of the differences, children need to learn how to handle those strong reactions and be able to build skills that help them express their emotions in more effective ways. In order to build these skills, participants explained that they often provide support for students until they are able to handle the challenges on their own. Examples could include, if a student is getting frustrated, staff may prompt them to get up and get a drink, or using a timer to get periodic breaks.

The ultimate goal for agency schools is for students to transition back into community schools. There are many other skills that students need to build in order to successfully integrate back when levels of support look very different. Laura described skills she teaches in order for youth to successfully navigate when they reintegrate back to community school,

Definitely independence and advocacy. I think those are the two that I push the most. There is no shame in asking for help, because I feel that when they transition out into community school... and absolutely no disrespect to 
community school, but they have such a large number of students. And I look at it that they are going to be 1 out of possibly 30 , and they have to be able to say, "I am sorry I didn't understand, could you write that down for me?", those kinds of things. I think self-advocacy is probably the biggest skill that we teach in here... and independence. Learning that they all have jobs when they come in. So, those are probably the two. And unfortunately, academics sometimes comes behind those things.

Independence and advocacy are two skills that I believe can be really difficult for students to develop. I have watched many students unfortunately struggle because they don't feel comfortable and confident enough to ask a teacher for assistance. There also may be many times, especially in a community school, when teachers are unable to fully support students when they need additional assistance. This could due to factors such as large class sizes of 20-30 students, with no additional support staff. When this is the case, it is crucial for students to develop independence to be able to work on their own.

Students coming from agency school support need to be able to adapt to no longer having the same number of supports they were receiving in an agency school.

There may be risk factors that students are facing that could impede their learning. This could include families living in poverty and not having enough money for food. Jane described the factors that may affect student's ability to learn, and the ways that the school helps students overcome barriers that may be inhibiting them from reaching success,

We have other programs that run, occupational therapy, food programs, healthy snack programs. Food is a big thing, and to me that's important because I've seen 
kids come to school with no lunch, or a bag of chips and a pop. So, I was a big proponent on getting this healthy snack program in my school because food is obviously related to your behaviour. If you're eating a ton of junk food or no food at all, that's going to affect your behaviour. Imagine trying to learn, or you never had breakfast and it's 10 o'clock in the morning, you're starving, and you can't learn. We're pretty good at picking up on what a child needs, and so once we get those basic needs met, then we can teach.

This is a strong component of teaching the whole child. Individuals need their basic needs met before they can begin to focus on things like academic success. Some of these additional programs mentioned by Jane are mirrored in community schools, such as healthy snack programs. This ensures that barriers to learning, such as feeling hungry and tired, are combated to help all students reach success. Additional programming is also a large part of some agency schools because it allows for youth to develop various skills in a different environment, other than a typical classroom. Patricia described the strengths and weaknesses that may start to evolve when outside of a typical classroom environment in their high school setting,

We offer a number of things to the kids here such as greenhouse, shop, co-op, working in the store. After some settling in time, and if the student is interested in those things, then they start going out into these activities. When they are doing that, we start noticing a lot of their strengths or weaknesses coming out in this different environment.

These types of different environments begin to promote building success in areas other than just academics, which is very crucial for students to understand the different ways 
that success can be defined. These students need to build skills that will help them become successful and independent adults. For many of these students, success will be going immediately into the workforce, finding work co-op programs, or developing a skilled trade. In an elementary school setting, these environments would look very different for a much younger demographic of students. Spaces outside of the classroom setting might look like more physical activity time in a gymnasium or outside. Some programs even have the option for swimming as a regular program incorporated into their weekly routines.

Teachers explained how working in an agency setting has now given them a new perspective on teaching. Although the student needs look different, they describe that if they were to ever teach in a community school setting, they would still put a very large emphasis on incorporating social and emotional learning into their daily practice. Their experiences have taught them that academics are only a small part of success for students, and there is a lot of other skills and learning that need to be focused on for all students to reach overall success.

\section{Theme 2: Communication}

Communication is viewed as one of the largest factors of success in an agency school setting. Whether it be communication within the interdisciplinary team, communication between the agency school and family, or communication between the agency school and the community school. It was clear from all participants that when there is strong communication happening, team members are able to more effectively meet the diverse needs of students in-risk. Teachers were asked the following questions that began the conversation of how crucial the role of communication is within their 
team, "How does your interdisciplinary team work together to plan for the success of your students" and "How does this team within the agency school collaborate with students' community school/teacher?". Vanessa described the continuous communication and collaboration that happens between all those involved with the student,

I would say we are very collaborative, nothing gets decided on its own. So, if a teacher wants to make a programming change, they would never just go ahead and change it. A team meeting would be called, and everybody would come together and talk about whether or not that is best for the student. If it is, this is how we proceed. So, lots of emails, lots of conversations.

When a student is dealing with various risk factors such a diverse range of needs, it is crucial to have a diverse team of professionals working with that student. As a teacher, I am constantly asking for assistance from fellow colleagues when I am unsure of how to deal with a situation. In order for these professionals to give students the best intervention possible for their needs, communication and teamwork are imperative. Working through a team approach is also a great model for children and youth to see in order to help develop their own ability to work together toward a common goal.

Some of the agency schools included in this research have a transition team who spoke of many successes with the communication they have with community schools. Heather explained how important communication is from the very beginning with community schools.

Okay so, as I mentioned they are involved right from the beginning. And that wasn't always our practice. It used to be, and even myself in the building, I use to become involved with the youth's team at sort of the final plan of care before the 
transition was going to take place. And over the years, what we found is the effectiveness of right from the beginning. So, right from the beginning, everyone is a part of that team. That way the school, from the intake point of view, they are able to share what is was looking like for that youth in the community school. What was presenting as the issue, what was tried, what was really getting in the way from their perspective. And then, they were able to follow along and see what different things the youth was working on here, what strategies they were building and how was it being implemented. So, I think in some ways that was learning for them as well. Because it's different when you receive the information, versus when you are a part of that conversation along the way. And then, they are involved right through and they help us create the plan. They would help us create the recommendations.

It was very interesting to not only listen to what is working successfully with continuous communication, but to also understand how the programs have evolved and made changes over time. Reflection is a crucial process to ensuring that program quality is continuing to meet the diverse and changing needs of students (People for Education, 2018; OME, 2017). The teachers in this research spoke very passionately about the ways they are able to adapt to the changing needs of the students. Heather builds on their process of reflection and program adaption by explaining a new program they have recently started in order to improve upon their current transition practices,

We have recently, actually through our transition group, also started some feedback from the students to get a sense of what was most helpful to them. And then a few years ago we also started gathering feedback from the key people that 
we work with, so more the go-to people in community schools and how they feel about the transition process. It's been insightful, and then it also allows us to continue to evolve in what we do.

Although the programs have strong practices, challenges may come up along the way. The teachers explained how no student profile is going to be the same, which means that each intervention and transition plan will be individually tailored. Heather explained how challenges come up during the transition process for students, but communication among all members of the team, as well as the community school is key to plan adjustments to be sure that the student is moving forward,

One of the challenges is because we can only go so far in experiencing the community school here, that sometimes we don't always know what will come up. So, some of the youth who jump into full time right away, we have that a lot. We would often have follow-ups where "okay this has come up and we weren't really anticipating it". And then, we're basically in the consultation role at that point, and the point of contact would be myself, or the others in the transition team. But, we have access to the full treatment team. So, we would do things like sometimes review the discharge plan. Did all the supports we thought would get in place, get in place? Did they hit a bump in the road related to something else and can we brainstorm? So, it could be three of four months after the student has gone full time, they may ask us if we can attend a meeting just to create a plan around how to help that student get through something that has come up. So, it again, can look very different, but we are absolutely available to the community schools. And that has evolved over time. It used to be where once they left, they 
left. That was just how it happened, but eventually we reviewed our process, and it made most sense that if they could at least connect and brainstorm and check in, it could help that youth and that family.

It was very interesting to hear that some schools are able to adapt and intervene even after a student has successfully transitioned into community school. I believe that this is an extremely beneficial process because student risk factors do not go away, and so despite the right tools, they may still have difficulties that can arise. Schools that did not have a transition team explained that there was some disconnect in communication, specifically after students transition back into community school. Sara described some areas where communication could improve,

We don't have a lot of communication after they leave. We might during their integration, a little bit, depending on what school it is, with the teacher and the principal. I've even emailed a few times "hey, how's everything going?", and sometimes we don't hear anything. And I get it, everyone is super busy, but we have a big disconnect after they leave, we really don't know how they are. Whether that's confidentiality, I don't know.

This leads me to wonder if this is a process that can be improved over time, or if there actually are barriers that do not allow these certain schools the opportunity to have as much communication and contact as they would like. When team members communicate with each other, they have the opportunity to fix issues that may come up that are interfering with the success of reaching the overall goal for their students. This also gives the opportunity to share and reflect upon experiences that will help to strengthen the programs. 


\section{Theme 3: Collaboration and Team Dynamics}

Teachers viewed the successful academic and overall achievement outcomes of students as being a result of the collective efforts of the interdisciplinary team. Teachers spoke very highly of the effectiveness of working as a team, and how the various professionals were able to give a different set of skills to meet the diverse set of student needs (Penney, 2011; OME, 2009). Jane explains that, "each member of the team just brings a lot to the table". When Patricia was asked to explain how the interdisciplinary team works together, she was very confident in her response, "that's what we do here, it's our programming and it's what we do". She further described how her team is constantly collaborating about how they can best meet the needs of each of their students,

Throughout the day, there isn't a moment that goes by where we're just kind of communicating, social worker is calling perhaps, and my CYW is relaying information to me, and then maybe I am needing to modify some work. Or, maybe we are needing to be a little bit flexible in our routine, if something has come up. Every day when the kids leave around 2:30, that is kind of our time to go through each individual kid and what their day is looking like, and what their goals are going forward.

It was wonderful to hear how much communication and collaboration is happening amongst team members. This is an approach that really needs to be adopted in all schools. Although the amount of supports looks very different in an agency school, versus in a community school, community school teachers are able to adopt this practice to an extent with the team members available. Some of these members in a community school would include the school CYW, early childhood educators, educational assistants, 
and developmental support workers. Each professional is able to bring a specific set of skills for students to thrive and develop the necessary skills in order to be successful. Sara explained how working alongside of a CYW each day has allowed for the development of better language skills when solving problems,

Our CYWs are trained in problem solving, so they really work well with giving the educators better language with how to really get down to the root of the problem. It's not that they don't want to do their math, maybe it's because they didn't have breakfast this morning and they are actually hungry. So, they give us better language that we are not trained in to get to that problem in a roundabout way that will get the student feeling more empowered. So, like, it's this big learning curve.

Jane explained how working alongside of a CYW and a social worker has given her skills that have not only helped her teaching practices, but also her parenting, I've learned a lot working with the CYWs, even with just raising my own children at home. The CYWs taught me how to talk to a child, and get them to understand you, and get down to their level. Different strategies to address certain issues. Social workers are great at talking with the children and getting them to open up and work through some deep-rooted issues. Sometimes I have even said to my staff, I need help. And I am not afraid to say that. Even though I have been working there forever, there are many situations that I am like, okay I've done what I can do, someone help me. We help each other all of the time.

Heather described how each individual team member is able to bring something different to the environment, 
I think the team, everyone brings a piece. Whether it be the social history, or what's happening at the home at any given time... we know how much of that comes in to the schools. And so, just having an awareness of that, I think is significant in helping the youth to be successful. I think that when you look at, whether it be trauma, or learning issues, or emotional regulation, everybody here within the team is building those skills. So, we have a lot going on in the classrooms in terms of building of skills, but then that carries over into the social work domain. And so, everybody working together I think is what makes it so rich because it's in every part of their day. As opposed to someone who might be attending outpatient... they are coming and getting the support here, but it's not necessarily translating, and I think what we've seen is that students need so much practice. When they know the skills, it's then practicing to really make them solid in being successful. So, I think having that here offers that as well, because they are getting it in every component of their day.

Many teachers explained that all of the practices and decisions are done through collaboration. Mia explained the type of collaboration and teamwork that happens when there may be an issue that arises with a student,

If something is going on, we will go through some type of therapy to deal with how we can get them back to school. So, there is just a lot of teamwork, if there is an issue with the student, it's not just me and the student, it's me and the whole team. So, there is a lot of teamwork at this school for sure.

When there are so many professionals collaborating together in one environment, the chances for student success drastically improves. Each member has a different set of 
skills that they can use to help solve challenges that may come up along the way. This dynamic is an excellent example of what we hope to see in all school environments with the various professionals that work in community schools.

\section{Theme 4: The Present Role of Parent(s) and/or Guardians}

The role of parent(s) and/or guardians is described as a key factor in determining student success. When parents are involved in a student's education, students have higher grades, school attendance, graduation rates, as well as they may experience higher selfesteem and self-efficacy, lower rates of aggression and violent behaviour, as well as overall well-being (Callahan, Pademacher, \& Hildreth, 1998; Henderson \& Mapp, 2002; OME, 2010). Coleman (1988) describes family and environment as the two main providers of social capital (Dika \& Singh, 2002). Teachers have the ability to influence forms of social capital through parental expectations and involvement, connections between families and school, the overall climate of the school, and cultural norms and values in school and the community (Acar, 2011).

Teachers were asked, "What role do parents or guardians have in this support process?", which started a lengthy discussion around the families of students who are receiving intervention. Some literature pointed to parents having very little engagement in alternative schools (Brown \& Beckett, 2007). However, the research I conducted presented the opposite. Not only is parental involvement a requirement set out by the OME for students to receive treatment, but the schools pride themselves in ensuring that parent(s) and/or guardians are involved and also receiving intervention themselves. In order for students to be admitted into day treatment, families are required to play a 
supportive role in the process. Sara described how there needs to be a willingness to receive treatment from all members in order to meet the acceptance criteria,

Families need to be on board for them to be in treatment. We're a little bit different because they have to be willing to want to get the help. So, there is a lot of criteria that they have to meet before they can even get into the program. Not necessarily only based on need... it's need and can you meet us in the middle and try to actually engage.

Although I believe that having this criterion increases the success rate for students, I do wonder if this eliminates the possibility for some students to ever receive treatment if they do not have the support of their families. I would be curious to understand what community schools are able to do for these types of students who may not be accepted into a day treatment setting, but still need some sort of intervention to succeed. Despite families being required to be a part of the treatment process, there is still a large spectrum of involvement that the agency schools see from the families. Teachers spoke about the lack of strong family support as a large risk factor. Jane describes how it can be a 'detriment' to some students if their families are not also willing to change and accept treatment,

They just want us to deal with it, they want us to fix everything, and sometimes that kind of comes back to haunt them because if the parent isn't involved and the child isn't progressing, things are either going backwards or not going anywhere. Sometimes they do get discharged from the program, not very often, but it happens. And sometimes the parent is almost like a detriment to the progress of the child, they're absolutely not on board at all, then they get discharged. And 
then the child unfortunately loses in that situation. Because the parent is still going to be the parent, but then the child still has to go back to community school not knowing what to do, or how to be successful. But, then there are other parents who do come to every meeting, communicate very well with all of the team players of the school. And it just makes everything so much easier. And the child actually senses that.

This adds to the issue I mentioned above that questions what types of interventions could help the students who are not receiving the family support that is required for treatment. When a child is undergoing treatment in agency schools, teachers do not have much contact with the parents, which is a very different process than in community school. However, Sara explained how parents are supported, as well as which members do keep in constant communication with them,

So, at our school, we have in home support workers. They do a lot of support for setting up routines, for setting up parents with parenting skills, things like that. As in how to deal with those behaviours at home and how to make their home life more structured. So, home support, in home support workers kind of deal with that more than I would. And a lot of communication is done through their social worker because they have a social worker, an in-home support worker, and a teacher.

Although teachers are not in direct contact with parent(s) and/or guardians, Heather explained the ways that teachers are involved with the team to be sure that proper communication and care is being relayed to the families, 
Parents are a big part of the program here. Each youth has an interdisciplinary team assigned to them. The social worker would be the primary person engaging with the parents on sort of a weekly communication with them, they would come in for sessions with the students. We would engage with the parents at Plan of Cares, or I might even be involved with a phone conference with the parents and the social worker. We try to keep it all interconnected because usually whatever we're talking about will carry over to whatever supports the social worker will provide. So, we try as much as we can to do it that way and they certainly are a big part of the team in terms of understanding the youth and what they need. And then helping them understand how they can get that when they move forward into the community school again when they don't have the entire team.

During treatment, families are given many supports. The supports not only serve as a tool of communication for progress of the child, but they also serve as intervention for the parent(s) and/or guardians themselves. Families may receive tools to help them with their parenting, as well as community resources and support that could help them with various risk factors. Mia explained how parents are not just involved in understanding the progress of their child, but they look to the staff for support,

I would say, that the parent's kind of look to us for support and for coping strategies and skills that we can give to them. That way they can have a more successful home life because sometimes their home life is tough with the anxiety and depression, and the opposition at home.

Teachers were asked “Are student's families more knowledgeable about their child's needs and the resources that are available to support them?”. Every teacher was very 
passionate to confidently explain that they pride themselves on ensuring parents are able to learn the skills necessary to help their children succeed once they are no longer in treatment. Heather explained why she believes parents are more knowledgeable, as well as further explains the types of intervention families receive,

I can with confidence say that it's definitely a significant goal while families are involved with us. As I mentioned, there's such a focus on the assessment and for us to get an understanding of the youth. And our goal as a team is to always help the parent with that as well so they can gain a strong understanding. Whether it be what might be getting in the way to self-regulate, or where they are in developing the skills, or for some parents it's a whole shift in how they start to see their son or daughter as a learner and their strengths and needs. Again, we're not always going to be there, so helping the families to help the youth is such a big part of what we do. And they're part of when we do a psychological assessment, or a neuropsychological assessment, families are always key in that process. Then when we see how that is playing out in class, then we can get that feedback to parents. And then offer we are helping parents to help the youth practice some of those skills we are teaching the youth at home because we know that when they are able to model those skills and practice those skills in multiple environments, it will really solidify those skills for the youth.

Assessment is a large piece of understanding the types of plans that will be developed for student treatment. Patricia described how parents are involved in order to help get them more knowledgeable about their children and what can be done to help them, 
The second that we go through assessment and an existing psych. report, or maybe we get a new type of assessment while they are here, our team does such a good job at delivering that information to the families. This will paint a picture explaining maybe why their child wasn't doing so well in community school, and this is what we've learned, and these are the skills we are going to work on. Often times, parents are on board, and they hear that feedback and they are thankful for that feedback. They wouldn't have known this and maybe it's why they weren't doing so well in community school, so absolutely they are more knowledgeable. It is definitely a part of the process. And even if it is not formal assessment, anything that is going on is in constant communication with the families. Although family involvement is a large part of the program, and is currently very successful, Jane spoke about what it ideally should look like to get families more involved in the treatment process,

I think ideally parents need to be at the school regularly too. We use to at previous agency schools have something called parent involvement. And for certain kids a parent or both parents would come during the day, and they would see how staff work with child, the language we use, the strategies we use, and then they would have some one on one time with their child, or with the social worker. And I really like that because you could tell a parent you know, this, this, and this. It is so helpful when they can see it and actually witness it. I think too kids are different at home than they are at school. So, they're going to be different with us than they are with their parents. But, if the child realizes that everybody is on the same page, and everybody is doing the same thing, I think that the success rate 
would be higher. I would love it if we could use the residential piece more. There used to be more involvement with families after school in the residence. And I think that was very helpful, because again, the more that parents can see how behavioural specialists actually deal with kids with behaviour problems, it just teaches the parents. And parents can take these techniques and use them in their own home.

I believe that this model would bring a lot of benefits to the program. In order for parent(s) and/or guardians to also gain the tools and skills necessary to help their child once they are no longer in treatment, they need to actually watch the strategies being used by professionals. We know that modeling is an effective approach of learning for children, and so it is also an approach that should be utilized for parents as well in order to really understand the tools and strategies that can be used at home. I also believe it would really help the child to see how invested their parent is in helping them succeed. This motivation could really help students overcome various challenges.

According to some research, parents of students facing various risk factors may lack the confidence to interact with school communities as they may feel stigmatized or judged (Fox, 2016). The goal of agency schools is to not only involve parents in the treatment process for their child, but help parents receive treatment supports as well. If parents are also able to receive the right supports, when students successfully transition out of an agency school, parents will hopefully have the right tools and knowledge to continue ensuring success for their child. 


\section{Theme 5: Successful and Adaptive Transition}

Treatment in an agency school is meant to be short term intervention, with the end goal being reintegration back into a community school (OME, 2019). Teachers spoke about how these programs are highly successful with giving students the necessary skills and tools in order to successful function in a community school after treatment, or in certain cases, finding alternative forms of success. When beginning this research, I was very curious to understand how we are helping students transition in and out of treatment. With the amount of support being so different at agency schools, compared to community schools, I was very curious to understand how exactly we prepare students to not only successfully transition back, but to also not be at a setback in comparison to the other students.

To begin the topic on student transitions, I asked teachers, "How does the transition process support the success of the students as they reintegrate into their community school" and "What resources are provided for students as they transition back into community schools?". With these guiding questions, teachers began to explain what the process of transition generally looks like. Vanessa explained what she has seen as the typical timeline for treatment, as well as what factors start to differentiate what it looks like between students,

Typically, a student would stay a minimum of a year because it would take that long to really understand their academic profile and their academic needs, and of course those coping strategies. Our mandate for sure is to have students transition back into the community school that they came from. That's the goal. But, some 
students depending on their needs might remain longer, some students might be shorter than a year.

Generally, when a student is transitioning back into community school, students complete a shared placement, which is where they will begin to transition into the community school part time, with the remainder of the time continued at the agency school. This was typical practice for both the elementary and secondary schools used in this research. Heather explained that a shared placement, where students gradually transition part time at each school, is usually the most effective way for students to transition,

I think we have seen a lot of success with the shared placement. I think students and families feel that it gives them the opportunity to get there in a positive way. We've seen youth gain a stronger understanding of themselves when they are here, so when they go back they are more confident learners and they've had some positive experiences that they are able to bring that back and continue in their community school placements.

Heather further explained that she believes this model is so successful because students are able to receive support and intervention, while they are trying to adjust to a new environment,

I think the shared model has worked so well because it maintains the support system while the youth take on additional challenges. So, I think that they still have all of the supports here as they are starting to practice with a different team, with a different physical environment with different challenges. We have youth that start out and run into something at community school, and they will bring it 
back to us to talk it through and solve how to move forward. And at first, we may be helping them by being that bridge between the school, and maybe contacting the school to help support them, but then as we move along we are trying to give them the tools to do that on their own. Instead of us being the person to call, they are going to their go-to person at the school.

Each plan is individually tailored to that specific student. Sara explained how the timeline that a student is attending day treatment is always different, as well as there are different reasons that they may be transitioning back,

So, the time always varies, for sure. And when it does get decided, it can be for different reasons that they might go back. It could be because they have met all of their goals, and they are doing fantastic, which is the ideal situation. You have skills, you have strategies, you can go in a regular classroom. I also have students that sometimes, this is the farthest that we can really bring you, we don't know if you could really do this independently, but you have some skills and you're are more settled at home and all of those things. And then we have students sometimes for lack of effort in the program, whether it's the student, or home, were just not ready for all of this intensive treatment, then they will go back to school.

It was interesting to hear Sara describe that some students are not ready for intensive treatment. This builds on Bandura's (1986) social cognitive theory, which includes an individual's behaviour being a factor of not only external reinforcement, but also internal reinforcement. Despite all of the supports available, a child and their family need to be open and willing to accept treatment. Another component of ensuring a successful 
transition is around the support received by the community schools. In order for a transition to be successful, Jane described how the community school needs to be willing and welcoming to accommodate the students and their complex needs,

We love when the community school is really welcoming of the student coming back. Sometimes, and I get it, some of these kids are very difficult, and so we try to share with them skills and strategies that they can take back to a community school. And we share, so I'll say all the things that I have used in the classroom so that the community school teacher can use those same strategies. Sometimes they will take our advice, and sometimes they don't, that's out of my hands. But we know that what we have, is kind of unrealistic to think that a community school can replicate exactly what we have here. We get that, but we also have to take the student from a crisis situation, from like the lowest of that child, and bring them up to a place where we think that they are ready to go. They have been with us for a year, year and a half, and now we have to pass the baton.

As a teacher myself, I do believe that sometimes there can be a lack of understanding of what is happening in agency school settings. This can lead to teachers not being prepared when they do experience students in their classroom who are transitioning from being in an agency school setting. Not only is it the role of the agency school to help prepare for the intervention of the child, but it is also the role of the community school. I believe Jane brought up a very important point where she describes how these students may always be facing challenges. These programs are an intervention for what Jane describes as "the lowest of that child", and so these programs will help students develop skills and tools that will help them better deal with their challenges, however it does not mean that those 
challenges completely go away. Back in community school they will still need support and guidance that will help them continue to overcome their risk factors and move towards success.

Transition teachers have a very unique role to help the students receiving treatment. Agency schools in high school settings have these positions to help students in-risk reach success. With some of the schools used in this research having transition teachers a part of their team, it was very interesting to hear how this additional role really benefits the process. Vanessa described this role, and how successful and beneficial it is for the students to have the additional supports,

For myself as a transition teacher, I am involved in every meeting. From the first meeting that they come into as a student, to the last meeting. So, I am consistent through the whole process and I will be able to talk about how they are doing in their classrooms, from the homeroom teacher being involved. As well as, any issues, behaviourally that they might face with the CYWs, those sorts of things. I know all the aspects of what they have done with their social worker, what's going on in the classroom, any peer issues, anything like that. I don't really work directly one on one, but I am more seen as a supportive role to those individuals.

I believe it is a real benefit to have an additional support role for these students who may not be working one on one with the child each day but is helping to develop suitable plans for that child when looking at the overall picture. Heather is another transition teacher, who built upon Vanessa's explanation confirming the unique support this role allows. She described that the transition role is continuous throughout students' entire time receiving treatment, 
When students first come into our program, I may be helping the team to collect information. I think a significant priority is doing a really thorough assessment of the students to guide our ability to create a program that best suites them for skill development, as well as leads to a more successful transition. So, I would help gather data, connect with the schools, connect with the team, and then from there I help support the classroom team and the treatment team to decide on a schedule for the student. What it's going to look like here, in terms of academics and what it will look like with their treatment program. Then throughout, I maintain involvement with the treatment team. I would attend all of the team meetings, and then I would also maintain that contact with the community school. We keep the community school involved throughout because we like to keep them informed throughout. And then just helping the teams along the way to determine if we had new assessment information that didn't fit what we initially had set up, how do we tweak that to make it more successful. And then at the point of transitioning out of our program, I would work with the team, which is myself, another transition teacher, and a transition CYW. So, we would be involved in taking the students on tours, reconnecting the school to identify go to people, getting them comfortable in the physical environment of the school, we would work with the families to help them understand what it's going to look like back in the school community environment. Because it looks so different right? Here, the classes are so small, and there are so many supports, so for them to take their advocacy skills and be able to transfer all of that out there is a really big step, and as it gets closer we see that anxiety increase. 
Mia explained the strategies that have been put in place specifically to help students attending treatment at the secondary level. Transition groups have been created to help students reflect on their transition experience and receive support not only from adults, but from their peers as well,

They will go once a week to a transition class with the social workers and they will talk about fears, and strategies to help them get ready for the next semester. So, they have that little transition meeting once a week to prepare them. Plus, we have met with the school, and they know we pick one or two classes to start. And then we fill out the form with the reinforcers, motivators, and goals. And then we just do that check in. So, when they are there, we check in and if there are any issues, we try to curb them before it happens. Each student has a contact at their new school, so they know if they have an issue, they can go to the LST office, or the guidance office, or the student success office.

This was a very unique strategy that I believe would have a very positive impact on a student's transition. Youth need to have peer acceptance, and so a process like this would really help students seek assistance and advice from youth around them, rather than solely the adults working with them.

Although these programs are built in a way that is saturated with many supports, there are still various challenges that can come up along the way. Two of the guiding questions in this interview were, "What challenges have you experienced as students' transition back into community school?" and What is the process if a student does not transition well back into community school?". It seemed that these two questions were the hardest questions to answer for the participants. It is very easy to reflect on the 
wonderful things that are happing in these programs and all the supports that are available; however, it is difficult and emotional to think of the challenges that can happen, as well as the worst situation where a youth is not successful in their reintegration process. Jane began to describe how some youth still have a very difficult time due to various challenges,

A couple of times, not very often they have actually come back. Like, shortly after. But I think that has only happened once or twice that I am aware of. Some students do return, and then within a year or two, they come back. So, it's not like once they are discharged, depending on their age, we only have kids until they're 13. So as long as they haven't aged out, we will take them back after a period of time.

Jane explained that the youth, "sometimes they feel like cut off, because they were a part of our family, and then they are taken away. So that is difficult for them to process". There are various factors for students that may get in the way of a successful transition, such as motivation and the mental health challenges. Despite receiving tools and strategies to help them cope, Mia describes how some students just cannot handle the transition,

We have so much structure here at this school, and so sometimes when kids don't have that structure, they crumble. It's like they need that structure. When it's more of their personal motivation, they can't do it. So, I would say sometimes after like a full-time transition, sometimes we hear that they have dropped out. I just think that it's more of the mental health that gets in the way usually. So, having that after care, making sure that when they are going to community school, 
that they are set up in the community with teen health, or they can still come here once a week for therapy, just to have that person to check in with. And I think they like being accountable with someone, it gives them motivation. So, I really just think that mental health support is really important.

Heather explained that some of these challenges may come from students trying to transfer the skills from such a small and supportive environment, to community school where there are less adults, more students, and more demands,

I would say for some of our youth, transferring our skills from here to there. Again, the larger environment, the social demands can be very challenging for the youth and so sometimes we will see that get in the way of their ongoing success. Or sometimes it's just a matter of that telling us we need to shift the plan a little bit. So, I would say that is a key. It is difficult for them, I would say to advocate for themselves, as much as that's our focus here. It is one that, I guess as adults even, it can be difficult.

Laura described the most difficult moment being when they are unable to help students succeed, even after every opportunity for support is given, I guess it can just be the breakdown where we are not able to help them, they don't want to be helped, so then they just leave. Parents aren't engaged, they're not engaged, every support in the school has gone to them, even tried to get them to do the outreach program, and they just don't want to do it.

It is clear that this would be the most challenging scenarios as an educator. The teachers did not speak of this situation coming up very often, however it is very unfortunate when 
despite all of the supports and tools the agency school team is trying, students are unable or unwilling to succeed.

Despite the challenges that come up, there are many options for these students. The team works together to figure out some sort of solution for student success. Each case is individual, and the final goal does not always have to be community school if it just is not working out for the students. Heather explains that there are alternative options for these students,

We have done some work with work-oriented programs, or in collaboration with the social workers because they are so knowledgeable in terms of financial resources that are available. Some of our youth stay until 18, and their goal isn't to go back to community school, it's work, or other community resources. So, we work closely with the social worker in that regard to figure out what makes sense as a next step. But, they would always leave with some transition plan, just what it looks like can be very different. We do, we have a lot go to college, and then workplace. Some youth considering University. And I don't know if this fits here, but with our grade 8 program, too, we always encourage them to start grade 9 here. So that is just another piece of creating successful transitions. That way we are able to help them start their pathway. And we do try to incorporate many of the things that the community school does. So, we will take the students to college and university tours. And again, it's all team based.

When students in-risk are a part of welcoming and positive environments with high expectations, they are able to overcome risk factors. It is crucial that students develop positive relationships with teachers and staff in order to feel supported (Aronowitz, 2005; 
Rak \& Patterson, 1996), especially through a hard adjustment such as a transition back into community school.

I can imagine how challenging working in an agency school setting could be. Despite the small class sizes, and the amounts of support, teachers are dealing with very challenging behaviours and situations on a daily basis. It is clear that it takes a certain teacher to work in this type of school environment. Every student comes with a very diverse set of risk factors and challenges that teachers need to try to mitigate. Despite the challenges that are faced throughout the process, teachers are able to reflect on the successes as being the most important thing. Laura reflects on how wonderful these programs are by describing two students she has previously worked with,

I guess I reflect back to my very first year. I had a boy, on the spectrum. Super negative, he had been here two years prior to me coming. "I can't learn, you're not going to make me learn, I don't want to learn”. Every day was negative. People would set him off just in just as they would come to the door... and he wouldn't be able to function or manage. I had him for my whole three years, the first three years that I was here. He transitioned to community school and he would walk from community school for one class and walk back over here. And he would come to the door and just stand "I hate this... this is the worst thing on the planet..." and he just could not manage at all. I am thinking to myself, oh my gosh we are pushing him out to do more. Mom was extremely, extremely smart and she couldn't understand why he can't get a $\mathrm{PhD}$. So, we worked really hard with her to say, “it's okay, he can have his successes in so many different ways. He has two siblings that again, one had their doctorate. He ended up going to 
community school full time, ended up with the principal's award and came out with like the highest mark in English! But the fact that he went out there and he came and was able to overcome all of that. He became independent and worked on the food line. That's the successes. Or we have watched kids, even one of my girls, I did not think she was going to manage. She was like, I am going to go on welfare, I don't need to do this. And then she gets a part time job! She is living not independently, she still lives in a group situation, but I didn't think she would ever have a job.

Listening to Laura tell this story about her student, I could hear the passion and emotion in her voice. It was clear how invested she was in her students, and how despite challenges that come up, and how difficult some days may be working with students with such a diverse set of difficulties, the moments of success are truly amazing. As teachers, we work for these moments; the moments that a teacher feels like they have a lasting impact on a student. Vanessa explains how in every case that she sees, there is always some kind of success,

I think each student that leaves here has their own success because although some might be bigger, and some might be smaller, they for sure have grown as an individual and with their coping skills and strategies and I think their life as a whole is better. At home is better, with their friends, they're managing school success for the first time in their life and they are feeling positive about their life. I believe that Vanessa's response truly encompasses what it means to be a teacher in any setting. Success is going to look very different for each student, and teachers need to be able to celebrate the differences that each of their students have. 
It is clear that agency school programs are able to provide a very effective and successful environment for students to reach the ultimate goal of transitioning back into a community school, or in some cases, finding alternative forms of success. When teams are able to build an effective partnership with community school supports, as well as build strong relationships with the students and all interdisciplinary team members, an optimal environment is created to help students overcome risk factors and challenges along the way. 


\section{CHAPTER 5}

\section{DISCUSSION}

The current study highlights the value and success of day treatment programs, and the resources provided as they transition back into community schools. Each of the seven participants in this research study had a unique perspective as they shared their rich experiences from their educational and professional lives. The participants shared their stories with me as an educator in an agency school setting, as well as they reflected upon

the importance of these experiences. All seven participants emphasized the importance of agency school settings, and the positive impact these types of mental health intervention programs can have on our education system.

The use of IPA allowed me to gain a rich and nuanced account of the lived experiences of the participants involved in this study. In order to better understand and analyze the data, I moved from a descriptive to an interpretative researcher. This allowed me to organize common themes based on the experiences of the participants. Five themes emerged from the data: 1) Teaching the Whole Child; 2) Communication; 3) Collaboration and Team Dynamics; 4) The Present Role of Parent(s) and/or Guardians; and 5) Successful and Adaptive Transition. These themes were recurring in the individual interviews and provided meaningful information on the successes of agency school programs and student transitions.

Much of the literature shares key attributes of agency schools and the importance of overcoming risk factors through resiliency, positive student-teacher relationships and social capital (Bourdieu, 1983; Bandura et al., 1961; Bandura, 1986; Coleman, 1988; Rak \& Patterson, 1996). 
In the following section, I will highlight my interpretations of the key findings by addressing the following research questions, as well as the limitations of the research and recommendations for the future.

1) How do teachers perceive their role working with students in-risk who are receiving treatment in agency schools?

2) How does a teacher's role affect the academic and overall achievement outcomes for students in-risk?

3) What types of programs and strategies are in place for a successful transition from treatment in an agency school, back into a community school?

Sub Questions:

- How effective is the transition into community schools?

\section{First Research Question}

How do teachers perceive their role working with students in-risk who are receiving treatment in agency schools?

Participants spoke very highly about their role as a teacher in an agency school. I received a very high response rate after my initial recruitment email was sent out, which gives me the impression that teachers are very motivated and eager to share their experiences in these positions. One guiding question I asked early on in the interview was, “In an ideal world, what would your ideal classroom look like?”. Looking back on the interviews, this served as one of the most important questions in my research because almost every teacher answered by explaining how the classroom they are currently teaching in is what they would describe as their ideal classroom. Their passion as an educator really came out as they answered this question. They spoke about the small class 
sizes, the amount of professional support, as well as the additional programming that made their classroom an ideal learning space for any student. Their answers also told me that these agency schools are really making a difference for students if they are able to collectivity and confidently say that these programs and strategies are what their ideal classroom would always look like in any school environment.

The literature was clear that teachers play a very important role in helping students overcome risk in their life when they are able to build secure and positive teacher-student relationships with their students (Ainswort, 1982; Hagenaur, Hascher \& Volet, 2015). These teachers understood that in order to for students to overcome risk factors and crisis situations, they must first feel safe and secure in their environment to develop the necessary self-esteem, self-efficacy, and resiliency skills. Students must also feel like they are understood at an interpersonal level. They require teachers who are empathetic to the challenges they may be facing.

Throughout my experience working with these agency school teachers, it became very clear that these teachers have a challenging role as they work with students with such a diverse set of needs. However, it is evident that these teachers are very passionate about their work, while encompassing strong empathy and compassion for their students. They emphasized the importance of building strong relationships, teaching the whole child, and working collaboratively with a diverse range of professionals in order to meet the needs of all of their students. Participants explained that being a teacher in an agency school has provided them with unparalleled learning experiences. It was very clear that these teachers want to share what they do each day with their students. They know that their interventions work, and they hope that this research will begin to open up the 
discussion of what goes on at agency schools for policy makers, administration, fellow teachers, and community members.

\section{Second Research Question}

How does a teacher's role affect the academic and overall achievement outcomes for students in-risk?

In order for students to reach overall success, students must develop a set of social and emotional skills outside of the academic curriculum (Swartz, 2017; Taylor, Oberle, Durlak \& Weissberg, 2017). Each teacher stressed the importance of social and emotional health and coping strategies. Many teachers emphasized that without these sets of skills, students would never be able to reach academic and overall success. Teachers really emphasized their goals of helping students develop the necessary skills to better manage stress, as well as get along with others. Their hope is that these students will not only be able to function in community school, but once they become adults, they will be able to live an independent and successful life.

Something that really stood out in these interviews was that teachers viewed the successful academic and overall achievement outcomes for students as being a result of the entire interdisciplinary team's role, rather than their individual role. Students in-risk have a very diverse set of risk factors, making it necessary to have a diverse team working with them to help them build the resiliency skills and tools to reach success (Highes \& Adera, 2006). Teachers spoke very highly of the effectiveness of working as a team, and how the various professionals were able to give a different set of skills to meet the diverse set of student needs. SCT explains that people learn from one another through observation, imitation, and modeling (Bandura et al., 1961; Bandura, 1986). When 
children and youth are surrounded by positive models, they may after time imitate this behaviour and develop protective factors and resiliency skills from watching others around them. With such a diverse set of skills amongst team members, students are able to develop the necessary skills that will not only help them succeed in a school setting, but also succeed in their life as a whole.

\section{Third Research Question}

What types of programs and strategies are in place for a successful transition from treatment in an agency school, back into a community school?

When developing transition plans, interdisciplinary teams must create and adapt plans based on individual student strengths and needs (OME, 2019). These teachers spoke about the extensive programs and supports being offered to students, as well as the continuous reflection happening in order to continue improving these services.

Some of the programs and strategies currently in place are, but are not limited to, shared placements, transition teams, as well as continuous support from interdisciplinary team members before, during, and after successful transition.

The programs and strategies differed as I compared the agency schools used in this research. For example, transition teams were available at the high school agency schools used, but not at the elementary schools used. These transition teams provided immense supports to students, however I can understand that there are factors that would limit these types of additional positions in all agency school settings. Despite the differences in certain strategies and supports, there are three strategies that stood out as being very effective at all of the schools interviewed in this research. 
The first effective strategy shared amongst each of the schools used was shared placement. Shared placement is where students slowly transition into a community school setting by splitting their time between both community and agency school, until it is believed that they are ready to integrate full time. This allows for the student to slowly be introduced to new challenges, while still receiving intervention support from their agency school. It also allows some flexibility in terms of readjustment to their goals if the transition is too difficult.

The second strategy that stood out as being effective for a positive transition was communication between team members and community school staff. Although this level varied between schools, it was evident that this was viewed as being important to all schools involved. When there is continuous communication and support before, during, and after agency school treatment, the team is able to provide a very effective treatment plan for the students. Some teachers spoke of this being a factor they wished they could improve upon.

The final strategy that stood out at all schools as effective was ensuring that the process was reflective and adaptive. Each teacher spoke about the importance of making changes to student plans when challenges would arise, as well as reflecting on the process as a whole. Teachers were able to introduce new strategies such as transition groups for students, as well as student feedback on intervention in order to continue to allow their programs to grow.

How effective is the transition into community schools?

It can be concluded that there are many strategies currently in place for a successful transition, and that the student transitions are viewed as being very effective. 
Although there were differences amongst the schools involved, and there are areas that the participants explained could be improved, it can be concluded that transitions are viewed successful as whole. Team members are constantly problem solving, adapting, and individualizing transition planning in order to meet the diverse needs of students inrisk.

It was very interesting to learn how many options there are for these students to be successful. Although the ultimate goal is for students to successfully transition back into community school, some students are just unable to reach that despite the support and strategies given. In those cases, these teams work together to figure out an option that will work for this student to be successful, whether that be other community supports, work and co-op programs, or adult mental health services. Transition plans are being developed and created amongst interdisciplinary team members and community supports based on students' strengths and needs in order to create the most appropriate goals for students, as well as to create the skills necessary for students to be successful in their lives.

\section{Recommendations}

Based on all teachers' perspective and literature review, I suggest the following recommendations.

Build a Relationship of Trust. Each teacher stressed the importance of communication between interdisciplinary team members and contacts at the community schools, however teachers did not mention the importance of building a relationship of trust. Although communication is key for constructing relationships, the effectiveness is minimal if these professionals do not trust one another's unique knowledge and expertise 
(Bryk \& Schneider, 2002; Gray, Kruse, \& Tarter, 2016). Trust provides a foundation for a successful and reciprocal relationship, and in order to build trust there needs to be an understanding of one another's identity and role (Bryk \& Schneider, 2002; Gray, Kruse, \& Tarter, 2016). This recommendation extends to community school administrators, teachers, and support staff also building trust in the expertise of agency school staff. As a result, this will move towards building a stronger partnership and continue to strengthen successful student transitions.

Emphasize Holistic Education. It is clear from the literature, as well as from evidence in this research that social and emotional learning is key to develop the necessary resiliency and coping skills that will help all students reach academic and overall success. However, there is little explicit mention of holistic education (Miller, 2016; Miller, 1990), as well the extension that needs to be present for this type of learning in all classrooms across the education system. Teachers are encouraged to reflect on the value of seeing every student as an individual first, where they are able to build a strong relationship in order to truly understand their strengths and weaknesses to reach success. Focusing on creating "whole" individuals will help students become well balanced in their outlook on life, as well as help them develop an understanding of themselves in relation to the world.

Knowledge of Agency School Environments. Teachers spoke about the importance of community members, families, as well as community school teachers requiring a stronger knowledge of what happens in agency schools. It is expressed that there is a stigma around mental health in children and the type of services being offered, and efforts cannot expand without significant support from these members. Literature 
also emphasizes that when it comes to mental health challenges and risk factors amongst children and adolescents, families sometimes fear criticism or judgment which can lead to not seeking services (Murray et. al., 2014). To gain clearer understanding of agency school program goals, more knowledge around the increase of mental health, as well as the services being offered amongst community members and all those involved in education would be beneficial.

I also believe that it would be beneficial if teacher candidates were able to complete student practicums in agency school settings, thus gaining incomparable experience around developing programs and strategies for students in-risk. This type of experience would not only build knowledge specific to agency school settings, but also knowledge that can be extended to any classroom setting.

\section{Suggestions for Future Research}

I recommend that future studies look to understand interdisciplinary team dynamics, the role of parent(s) and/or guardians in this support process, as well as similar research studies. The successes of the interdisciplinary team were brought up many times by teachers and were even regarded as one of the most important factors for program success in agency schools. Some of these professionals include child and youth workers, social workers, psychologists, child psychiatrists, and various therapists. I believe a future study involving the perspectives of all of these team members would be very beneficial to better understand their successes and challenges, as well as the types of dynamics that can be extended into community school programs. Each member is trained in a different skill set and role, therefore each member brings a very unique perspective of agency school success. 
Other research that could offer tremendous benefits could look to understand the role of parent(s) and/or guardians in this process. This was a theme that emerged in the data, however this study only gained the perspective of teachers. Students must undergo an application process in order to be accepted into day treatment programming, and one of the main criteria for acceptance is support from parent(s) and/or guardians. The program looks to not only help students gain the necessary resiliency and coping skills, but to also help families build these skills as well. Teachers explained that this can become a challenge for many students and their families. Gaining the perspective of social workers who are deeply involved with the families, as well as even the perspective of parent(s) and/or guardians would be very beneficial.

The final recommendation is for the need for additional research to be conducted similar to this study. The current research study is the first, to my knowledge, to investigate the perspective of teachers working in agency school settings in Ontario. It is recommended that future studies continue to investigate this topic, perhaps on a larger scale, or as a comparative study in various school boards across the entire province. 


\section{CHAPTER 6}

\section{CONCLUSION}

Agency schools play an important role in the education system. These intervention programs assist with meeting the goal of helping all students reach success, regardless of their needs and risk factors. The agency schools involved in this study have been shown to be a very successful intervention for students experiencing serious emotional, social, developmental, and/or behavioural issues. The aim of the current study was to present and interpret the perspective of teachers for policy makers, administrators, and researchers to develop a deeper understanding of the structure and dynamics of day treatment programs and transitions, so that agency schools can continue to develop to meet the needs of students in-risk. Literature examining students in-risk have implied that resiliency, SEL, positive student-teacher relationships and role models, as well as social capital can have successful effects of mitigating various challenges and risk factors (Bandura et al., 1961; Bourdieu, 1983; CASEL, 2017; Coleman, 1988; Domitrovich et al., 2017).

As mentioned previously, I do not know of any other studies that investigate teachers' perceptions of agency schools and successful transitions. In fact, no studies have been found with teacher perceptions in Ontario. This study helps to address a gap in the literature. A qualitative case study was used in order to understand this topic and identify recommendations for future practice and research. The participants consisted of seven teachers currently teaching in agency schools in a school board in Southwestern Ontario. I was able to collect rich and meaningful data from these participants because 
they each had a great deal of lived experiences to share working with students receiving day treatment in agency schools.

Through IPA analysis, five themes emerged from the data: 1) Teaching the Whole Child; 2) Communication; 3) Collaboration and Team Dynamics; 4) The Present Role of Parent(s) and/or Guardians; and 5) Successful and Adaptive Transition. The themes present a general conception of how teachers identify their role in agency schools, while providing evidence of the success of day treatment programs and student transitions. It is not surprising that these educators spoke to these themes in depth. Together, they encompass what takes to create a successful school environment. The themes discovered in this research helped to produce important recommendations for future practice and research.

Positive psychology was used as a foundation for this research in order to understand a strengths-based approach of agency schools and student transitions. In the current study, all participants self-identified agency schools as positive interventions for students. This investigation of teacher perspectives provides insight into the understanding of agency school programs and student transitions, as well as insight into the role that teachers have in a setting like this. The current study allowed participants the opportunity to reflect upon their experiences, consider their own attitudes towards programs and transitions, and discuss their future roles as agency school teachers.

In addition, the current study contributes to the field of special education in Ontario by giving a voice to special education teachers working in agency school settings. The hope from this study is for individuals to become more knowledgeable about mental health interventions in schools, so that these programs can continue to 
advance. The hope is that the findings and recommendations of this study not only benefit those in agency school settings, but also educators in community school settings.

Mental health challenges and diverse risk factors continue to rise amongst children and youth (MHASEF Research Team, 2015). It is an unrealistic expectation for all teachers to be able to learn about every type of diversity and risk factor that they will encounter in their classroom. However, it can be suggested that the more we seek to integrate teaching holistic education and SEL into our everyday teaching, as well as the more that we try to educate teachers and community members about services being offered, the more awareness and success teachers will bring for students who may be facing various risk factors, as well as social, emotional, developmental and behaviour difficulties. 


\section{REFERENCES}

Acar, E. (2011). Effects of social capital on academic success: A narrative synthesis. Educational Research and Reviews, 6(6), 456-461. Retrieved from http://www.academicjournals.org/article/article1379690850_Acar.pdf

Archambault, I., Janosz, M., Dupéré, V., Brault, M. C., \& Andrew, M. M. (2017).

Individual, social, and family factors associated with high school dropout among low-SES youth: Differential effects as a function of immigrant status. British Journal of Educational Psychology, 87(3), 456-477.

Aronowitz, T. (2005). The role of "envisioning the future" in the development of resilience among at-risk youth. Public Health Nursing, 22(3), 200-208. doi:10.1111/j.0737-1209.2005.220303.x

Aronson, B., \& Laughter, J. (2016). The theory and practice of culturally relevant education: A synthesis of research across content areas. Review of Educational Research, 86(1), 163-206.

Avramidis, E., Bayliss, P., \& Burden, R. (2000). A survey into mainstream teachers' attitudes towards the inclusion of children with special educational needs in the ordinary school in one local education authority. Educational psychology, 20(2), $191-211$

Bandura, A. (1977). Social learning theory. Engelwood Cliffs, N.J.: Prentice-Hall.

Bandura, A. (1986). Social Foundations of Thought and Action: A Social Cognitive Theory. Prentice Hall.

Bandura, A., Ross D., \& Ross S. (1961). Transmission of Aggression 
Through Imitation of Aggressive Models. Journal of Abnormal and Social Psychology, 63(3), 575-582. http://dx.doi.org/10.1037/h0045925

Bennett, C. (1995). Comprehensive multicultural education: Theory and practice (3rd ed.). Massachusetts, MA: Allen \& Bacon.

Bennett, S., Weber, K. J., \& Dworet, D. (2013). Special Education in Ontario Schools (7th ed.). Toronto, ON: Highland Press.

Berkowitz, R., Moore, H., Astor, R. A., \& Benbenishty, R. (2017). A Research Synthesis of the Associations Between Socioeconomic Background, Inequality, School Climate, and Academic Achievement. Review of Educational Research, 87(2), 425-469. https://doi.org/10.3102/0034654316669821

Bourdieu, P. (1986). The forms of capital. In J. Richardson (Ed.), Handbook of Theory and Research for the Sociology of Education, 241-258. Westport, CT: Greenwood Press.

Brimblecombe, N., Knapp, M., Murguia, S., Mbeah-Bankas, H., Crane, S., Harris, A., ... \& King, D. (2017). The role of youth mental health services in the treatment of young people with serious mental illness: 2-year outcomes and economic implications. Early Intervention in Psychiatry, 11(5), 393-400.

Brinkworth, M. E., Mcintyre, J., Juraschek, A. D., \& Gehlbach, H. (2018). Teacherstudent relationships: The positives and negatives of assessing both perspectives. Journal of Applied Developmental Psychology, 55, 24-38.

doi:10.1016/j.appdev.2017.09.002

Brown, L. H., \& Beckett, K. S. (2007). Parent Involvement in an Alternative School for 
Students at Risk of Educational Failure. Education and Urban Society, 39(4), 498-523. doi:10.1177/0013124507301579

Bryk, A.S., \& Schneider, B. (2003). Trust in schools: A core resource for school reform. Educational Leadership, 60(6), 40-45.

Cabaj, J. L., McDonald, S. W., \& Tough, S. C. (2014). Early childhood risk and resilience factors for behavioural and emotional problems in middle childhood. BMC Pediatrics, 14(1). Retrieved from http://link.galegroup.com.ezproxy.uwindsor.ca/apps/doc/A539592312/AONE?u= wind05901\&sid=AONE\&xid=b1367575

Callahan, K., Rademacher, J.A., \& Hildreth, B.L. (1998). The effect of parent participation in strategies to improve the homework performance of students who are at risk., Remedial and Special Education 19(3), 131-141.

Campie, P.E., Pakstis, A., Flynn, K., \& McDermott, K. (2015). Developing a coherent approach to youth well-being in the fields of child welfare, juvenile justice, education, and health: A systematic literature review. Families in Society: The Journal of Contemporary Social Services, 96(3), 175-184.

CASEL. (2018). Core SEL Competencies. Retrieved from https://casel.org/wpcontent/uploads/2017/01/Competencies.pdf

Claymore, K. (2017). Adjusting for Inclusion: The Importance of Training and Education for Mainstream Teachers who Instruct Children with Autism Spectrum Disorder (Doctoral dissertation, State University of New York Empire State College).

Coleman, J. S. (1988). "Social Capital in the Creation of Human Capital." American 
Journal of Sociology 94 (supplement):95-120.

Creswell, J. W. (2007). Qualitative Inquiry and Research Design: Choosing Among Five Approaches (2nd ed.). Thousand Oaks, CA: Sage Publications.

Crocker, R. (2000). Pan-Canadian Education Research Agenda. Symposium report: Children and youth at-risk. Statistics Canada: Canadian Education Statistics Council, 1-165.

Darling-Churchill, K. E., \& Lippman, L. (2016). Early childhood social and emotional development: Advancing the field of measurement. Journal of Applied Developmental Psychology, 45(Complete), 1-7.

doi:10.1016/j.appdev.2016.02.002

Davis, T. S., Guada, J., Reno, R., Peck, A., Evans, S., Sigal, L. M., \& Swenson, S. (2015). Integrated and culturally relevant care: a model to prepare social workers for primary care behavioral health practice. Social work in health care, 54(10), 909-938.

Dika, S. L., Singh, K. (2002). Applications of social capital in educational literature: A critical synthesis. Rev. Educ. Res., 72(1): 31-60.

Domitrovich, C. E., Durlak, J. A., Staley, K. C., \& Weissberg, R. P. (2017). SocialEmotional competence: An essential factor for promoting positive adjustment and reducing risk in school children. Child Development, 88(2), 408-416. doi:10.1111/cdev.12739

El-Radhi, A. S. (2015). Management of common behaviour and mental health problems. British Journal of Nursing, 24(11), 586-590. doi:10.12968/bjon.2015.24.11.586

Esterberg, K. G. (2002). Qualitative methods in social research. Boston: McGraw-Hill. 
Finlay, L. (2011). Phenomenology for therapists: Researching the lived world, Chichester: Wiley-Blackwell.

Fox, M. (2016). Challenging the Concept of Cultural Deficit, Through a Framework of Critical Based Education. Global Observatory for Inclusion, 88(5), 638-647.

Friend, M., Cook, L., Hurley-Chamberlain, D., \& Shamberger, C. (2010). Co-teaching: An illustration of the complexity of collaboration in special education. Journal of educational and psychological consultation, 20(1), 9-27.

Gardner, R. L., \& Stephens-Pisecco, T. L. (2019). Fostering childhood resilience: A call to educators. Preventing School Failure: Alternative Education for Children and Youth, 1-8. doi:10.1080/1045988x.2018.1561408

Gay, G. (2002). Preparing for culturally responsive teaching. Journal of Teacher Education, 53(2) 106-116

Gray, J., Kruse, S., \& Tarter, C. J. (2016). Enabling school structures, collegial trust and academic emphasis: Antecedents of professional learning communities. Educational Management Administration \& Leadership, 44(6), 875-891. https://doi.org/10.1177/1741143215574505

Greenberg, M. T., Dornitrovich, C. E., Weissberg, R. P., \& Durlak, J. A. (2017). Social and emotional learning as a public health approach to education. The Future of Children, 27(1), 13+. Retrieved from http://link.galegroup.com.ezproxy.uwindsor.ca/apps/doc/A503262646/AONE?u= wind05901\&sid $=$ AONE\& $\&$ id $=$ bdbb 8430

Gronholm, P. C., Nye, E., \& Michelson, D. (2018). Stigma related to targeted schoolbased mental health interventions: a systematic review of qualitative 
evidence. Journal of affective disorders.

Hagenauer, G., Hascher, T., \& Volet, S. E. (2015). Teacher emotions in the classroom: associations with students' engagement, classroom discipline and the interpersonal teacher-student relationship. European Journal of Psychology of Education, 30(4), $385-403$.

Haine-Schlagel, R., \& Walsh, N. E. (2015). A Review of Parent Participation Engagement in Child and Family Mental Health Treatment. Clinical Child and Family Psychology Review, 18(2), 133-150. doi:10.1007/s10567-015-0182-x Hartwick, O. \& Kubisiak, K. (2014). The effects of an at-risk label on the attribution of student behavior. UWL-Journal of Undergraduate Research. Retrieved from https://www.uwlax.edu/urc/jur-online/PDF/2014/Kubisiak.Kathleen.PSY.pdf.

Heidegger, M. (1985). History of the concept of time. Indiana University Press.

Henderson, A. T., \& Mapp, K. L. (2002). A new wave of evidence: The impact of school, family, and community connections on student achievement. Annual Synthesis, 2002. Austin, TX: National Center for Family and Community Connections with Schools and the Southwest Educational Development Lab. Retrieved from the SEDL website: https://www.sedl.org/connections/resources/evidence.pdf Hughes, A. F., \& Adera, B. (2006). Education and Day Treatment Opportunities in Schools: Strategies That Work. Preventing School Failure: Alternative Education for Children and Youth, 51(1), 26-30. doi:10.3200/psfl.51.1.26-30

Husserl, E. (1970). The crisis of European Sciences and Transcendental Phenomenology: An introduction to phenomenological philosophy. (translated by Carr, D.) Evanston: Northwestern University Press. 
James, C (2002). "You can't understand me: Negotiating teacher-student relationships in urban schools. Contact: 28(2), pp. 8-20.

Javed, Javed, \& Khan. (2016). Effect of Education on Quality of Life and Well Being. International journal of Indian psychology. 3. 2349-3429. Jones, S. M., Zaslow, M., Darling-Churchill, K. E., \& Halle, T. G. (2016). Assessing early childhood social and emotional development: Key conceptual and measurement issues. Journal of Applied Developmental Psychology, 45, 42-48. doi:10.1016/j.appdev.2016.02.008

Kinsella, W. \& Senior, J. (2008). Developing inclusive schools: a systematic approach. International Journal of Inclusive Education, 12, pp. 651-65

Kirby, L.D. \& Fraser, M.W. (1997). Risk and Resilience in Childhood, in M. Fraser (ed.) Risk and Resilience in Childhood: An Ecological Perspective, 10-33. Washington, DC: NASW Press.

Levinson, M. (2009) Mapping Multicultural Education, in Harvey Seigel, (ed.) The Oxford Handbook of Philosophy of Education. Oxford University Press. Masten, A. S. (2011). Resilience in children threatened by extreme adversity: Frameworks for research, practice, and translational synergy. Development and Psychopathology, 23(02), 493-506. doi:10.1017/s0954579411000198

Masten, A. S. (2018). Resilience theory and research on children and families: Past, present, and promise. Journal of Family Theory \& Review, 10(1), 12-31. doi:10.1111/jftr.12255

Martin, A. J., Bottrell, D., Armstrong, D., Mansour, M., Ungar, M., Liebenberg, L., \& 
Collie, R. J. (2015). The role of resilience in assisting the educational connectedness of at-risk youth: A study of service users and non-users. International Journal of Educational Research, 74, 1-12. doi:10.1016/j.ijer.2015.09.004

McCarthy, Daniel D. P., Debbe D. Crandall, Graham S. Whitelaw, Zachariah General \& Leonard J. S. Tsuji. (2011). “A Critical Systems Approach to Social Learning: Building Adaptive Capacity in Social, Ecological, Epistemological (SEE) Systems." Ecology and Society 16(3).

McMahon, T., Ward, N., Kline Pruett, M., Davidson, L., \& Griffith, E. (2000). Building full-service schools: Lessons learned in the development of interagency collaboratives. Journal of educational and Psychological Consultation, 11(1), 6592.

McWhirter, J., McWhirter, B. T., McWhirter, E. H., \& McWhirter, A. C. (2017). At Risk Youth. Cengage Learning.

MHASEF Research Team. (2015) The Mental Health of Children and Youth in Ontario: A Baseline Scorecard. Institute for Clinical Evaluative Sciences.

Miller, R. (1990). Beyond reductionism: The emerging holistic paradigm in education. The Humanistic Psychologist, 18(3), 314-323. http://dx.doi.org.ledproxy2.uwindsor.ca/10.1080/08873267.1990.9976898

Miller, J. (2016): Equinox: portrait of a holistic school, International Journal of Children's Spirituality, DOI: 10.1080/1364436X.2016.1232243

Miller, A. L., Gearhardt, A. N., Fredericks, E. M., Katz, B., Shapiro, L. F., Holden, K., ... 
Lumeng, J. C. (2018). Targeting self-regulation to promote health behaviors in children. Behaviour Research and Therapy, 101, 71-81.

doi:10.1016/j.brat.2017.09.008

Mishra, S. (2016). Role of education in growth and development of the society. Splint International Journal of Professionals, 3(7), 84-91. Retrieved from https://searchproquest-com.ledproxy2.uwindsor.ca/docview/1906048374?accountid=14789

Murray, K. W., Finigan-Carr, N., Jones, V., Copeland-Linder, N., Haynie, D. L., \& Cheng, T. L. (2014). Barriers and facilitators to school-based parent involvement for parents of urban public middle school students. SAGE open, 4(4), 2158244014558030 .

Murray, C., \& Malmgren, K. (2005). Implementing a teacher-student relationship program in a high-poverty urban school: Effects on social, emotional, and academic adjustment and lessons learned. Journal of School Psychology, 43(2), $137-152$.

Newberry, M. (2010). Identified phases in the building and maintaining of positive teacher-student relationships. Teaching and Teacher Education, 26(8), 16951703. doi:10.1016/j.tate.2010.06.022

Noddings, Nel. (2005). What Does It Mean to Educate the Whole Child?. Educational Leadership. 63.

Ogundele, M. O. (2018). Behavioural and emotional disorders in childhood: A brief overview for paediatricians. World Journal of Clinical Pediatrics, 7(1), 9-26. doi:10.5409/wjcp.v7.i1.9

Ontario Ministry of Education. (2003). Building pathways to success: The report of the 
program pathways for students at risk work group. Retrieved from:

https://www.edu.gov.on.ca/eng/document/reports/pathways.pdf

Ontario Ministry of Education. (2010a) Caring and Safe Schools in Ontario. Retrieved from:http://www.edu.gov.on.ca/eng/general/elemsec/speced/Caring_Safe_School. pdf

Ontario Ministry of Education. (2009a). Essential Elements for Education Programs for Pupils in Government-Approved Care And/or Treatment, Custody, and Correctional Facilities. Retrieved from the Ontario Ministry of Education website: http://www.bwdsb.on.ca/stserv/downloads/Essential_Elements_Feb-02-09.pdf

Ontario Ministry of Education. (2019). Guidelines for Approval and Provision of Care and/or Treatment, Custody and Correctional (CTCC) Programs. Retrieved from: http://www.bwdsb.on.ca/stserv/downloads/Essential_Elements_Feb-0209.pdf

Ontario Ministry of Education. (2009b). Ontario's Equity and Inclusive Education Strategy. Retrieved from https://www.bwdsb.on.ca/stserv/downloads/Essential_Elements_Feb-02-09.pdf

Ontario Ministry of Education. (2017). Ontario's Education Equity Action Plan.

Retrieved from the Government of Ontario website: http://www.edu.gov.on.ca/eng/about/education_equity_plan_en.pdf

Ontario Ministry of Education. (2010b). Parents in partnership: A parent engagement policy for Ontario schools. Retrieved from the Government of Ontario website: http://www.edu.gov.on.ca/eng/parents/involvement/PE_Policy2010.pdf Ontario Ministry of Education. (2011). Section 23 regular program. Retrieved 
From http://faab.edu.gov.on.ca/Section\%2023.htm

Pazaratz, D. (1998). The counseling role of the child and youth worker in a treatment classroom. Adolescence, 33(132).

People for Education (2018). Annual report on Ontario's publicly funded schools. Retrieved from: https://peopleforeducation.ca/wpcontent/uploads/2018/06/AnnualReport18_Web.pdf

Penney, R. (2011). Mental Health "Day Treatment Services" For Adolescents with Emotional and/or Behavioural Problems. Retrieved from: http://www.excellenceforchildandyouth.ca/sites/default/files/gai_attach/EPG1299_Final_Outcomes_Report.pdf

Pietkiewicz, I., \& Smith, J. A. (2014). A practical guide to using interpretative phenomenological analysis in qualitative research psychology. Psychological Journal, 20(1), 7-14.

Rak, C. F., \& Patterson, L. E. (1996). Promoting Resilience in At-Risk Children. Journal of Counseling \& Development, 74, 368-373.

Richards, H. V., Brown, A. F., \& Forde, T. B. (2007). Addressing diversity in schools: Culturally responsive pedagogy. Teaching Exceptional Children, 39(3), 64-68.

Richards, M. M., Bowers, M. J., Lzaicki, T., Krall, D., \& Jacobs, A. K. (2008). Caregiver Involvement in the Intensive Mental Health Progam: Influence on Changes in Child Functioning. Journal of Child and Family Studies, 17, 241-252.

Richmond, W. (1975). Education and Schooling. London: Routledge, https://doi.org/10.4324/9780429440472

Sanders, J., Munford, R., \& Liebenberg, L. (2016). The role of teachers in building 
resilience of at risk youth. International Journal of Educational Research, 80, $111-123$.

Schleiermacher,F. (1998). Hermeneutics and criticism and other writings(A. Bowie, Trans.). Cambridge: CUP.

Schonert-Reichl, K. (2000). Children and youth at risk: Some conceptual considerations. In PECERA Symposium report: Children and Youth at Risk. Canadian Education Statistics Council. 9-10.

Simon, B. (2001). Family involvement in high school: Predictors and effects. NASSP Bulletin, 85(627), 8-19.

Smith, J. A., \& Osborn, M. (2007). Interpretative phenomenological analysis. In Qualitative Psychology (pp. 54-80). LA: SAGE.

Smith, J.A , Flowers, P. and Larkin, M. (2009) Interpretative Phenomenological Analysis: Theory, Method, Research. London: Sage

Sanders, J., Munford, R., \& Liebenberg, L. (2016). The role of teachers in building resilience of at risk youth. International Journal of Educational Research, 80, 111-123. doi:10.1016/j.jjer.2016.10.002

Stephan, S. H., Sugai, G., Lever, N., \& Connors, E. (2015). Strategies for integrating mental health into schools via a multitiered system of support. Child and Adolescent Psychiatric Clinics, 24(2), 211-231.

Stevenson-Taylor, A. G. K., \& Mansell, W. (2012). Exploring the role of art-making in recovery, change, and self-understanding---an interpretative phenomenological analysis of interviews with everyday creative people. International Journal of Psychological Studies, 4(3), 104. 
Swartz, M. K. (2017). Social and Emotional Learning. Journal of Pediatric Health Care, 31(5), 521-522. doi:https://doi.org/10.1016/j.pedhc.2017.06.001

Taylor, R. D., Oberle, E., Durlak, J. A., \& Weissberg, R. P. (2017). Promoting Positive Youth Development Through School-Based Social and Emotional Learning Interventions: A Meta-Analysis of Follow-Up Effects. Child Development, 88(4), 1156-11171. doi:https://doi.org/10.1111/cdev.12864

The Learning Partnership (2004) The Quality of Public Education in Canada: Who is at Risk? A Continuing Series of Progress Reports from The Learning Partnership. Retrieved from www.thelearningpartnership.ca/files/download/cf67451adaf0107

The Learning Partnership (2009) The Quality of Public Education in Canada: Resilience. A Continuing Series of Progress Reports from The Learning Partnership. Retrieved from http://fr.thelearningpartnership.ca/what-we-do/knowledgemobilization/building-resilience-in-children-and-youth

Trypuc, B. \& Heler, A. (2008) Breaking the Cycle of Failure. Charity Intelligence Canada. Retrieved from: https://www.charityintelligence.ca/images/Ci_EducationReport_08.pdf

Tuffour, I. (2017). A Critical Overview of Interpretative Phenomenological Analysis: A Contemporary Qualitative Research Approach. Journal of Healthcare Communications, 02(04). doi:10.4172/2472-1654.100093

Uitto, M., Lutovac, S., Jokikokko, K., \& Kaasila, R. (2018). Recalling life-changing teachers: Positive memories of teacher-student relationships and the emotions involved. International Journal of Educational Research, 87, 47-56. doi:10.1016/j.ijer.2017.11.004 
Van Voorhis, F.L. (2001). Interactive science homework: An experiment in home and school connections. NASSP Bulletin, 85(627), 20-32

Williamson, A., \& Witzel, B. S. (2016). Instilling resilience in children of poverty. The Wintrhrop McNair Research Bulletin, 2(13), 70-76.

Wood, K. (2011). Education: The basics. the basics Routledge, Taylor \& Francis Group. 7625 Empire Drive, Florence, KY 41042. Retrieved from https://search-proquestcom.ledproxy2.uwindsor.ca/docview/964183415?accountid=14789

Yates, T., Ostrosky, M. M., Cheatham, G. A., Fettig, A., Shaffer, L., \& Santos, R. M. (2008). Research synthesis on screening and assessing social-emotional competence. Retrieved from Center on the Social Emotional Foundations for Early Learning http://csefel. vanderbilt.edu/documents/rs_screening_assessment.pdf.

Zimmerman, E., Woolf, S., Haley, A. (2014). Understanding the Relationship Between Education and Health. Discuss. Pap. Roundtable Popul. Health, Inst. Med. Washington, DC: Natl. Acad. Sci. Retrieved from http:/www.iom.edu/ Global/Perspectives /2014/UnderstandingTheRelationship.aspx 


\section{APPENDICES}

\section{Appendix A: Definition of Key Terms}

Agency School. Agency schools are a type of alternative schooling that blends education with day treatment programs. Students are temporarily placed in these settings for exhibiting various risk characteristics and circumstances that lead to social, emotional, developmental and/or behavioural issues that inhibit them from being able to attend mainstream schools. Teachers work alongside various professionals such as child and youth workers, psychologists, and social workers from relevant agencies (OME, 2019).

Behaviour Plan. A written plan designed to target the underlying reason for behaviour and replace the behaviour with one more appropriate (OME, 2010).

Day Treatment. Day treatment is a partial hospitalization program joint with education for those individuals with serious mental, emotional, developmental, and/or behavioural issues (OME, 2017, OME, 2019). These services are designed to prevent movement to a more intensive level of care (OME, 2017; OME, 2019). Although treatment is a medical term, it is used in this research to keep consistent with policy documents in Ontario, as well as the language used by the professionals interviewed in this research.

Individualized Education Plan (IEP). An IEP is a written plan outlining the special education services required by a student, based on their strengths and needs (OME, 2010).

Students In-Risk. Students can be deemed "at-risk", “in-risk”, or "high-risk" when they lack resiliency skills necessary to overcome various risk factors. These terms are 
used interchangeably to address the degree of intervention and support required for students at risk of academic failure. For the purpose of this research, students attending alternative education in agency schools would be defined as "in-risk", as they are currently unable to succeed in mainstream schooling due to various characteristics or conditions.

Risk factor. Risk factors are attributes, characteristics or exposures that increase an individual's likelihood of academic failure or failure to complete high school (Hughes \& Adera, 2006; The Learning Partnership, 2004).

Safety Plan. A written plan is developed for a student whose behaviour poses an ongoing risk to themselves, other students, or staff (OME, 2010). 


\section{Appendix B: Interview Questions}

1. How long have you been a teacher in an agency school setting? How would you describe this role?

2. What types of challenges are these students faced with?

3. What supports do you provide for the students?

4. What role do parents or guardians have in this support process?

5. In an ideal world, what would your ideal classroom look like?

6. How does your interdisciplinary team work together to plan for the success of your students?

7. How does this team within the agency school collaborate with students' community school/teacher?

8. What does a typical day look like for these students? How does it differ from the average community school day?

9. What types of skills are you trying to teach these students?

10. How does the transition process support the success of the students as they reintegrate into their community school?

11. What resources are provided for students as they transition back into community schools?

12. What successes have you experienced as students' transition back into community schools?

13. What challenges have you experienced as students' transition back into community schools? 
14. What is the process if a student does not transition well back into their community school?

15. Are there additional supports and resources that would assist teachers as they help students transition back into community schools?

16. Are student's families more knowledgeable about their child's needs and the resources that are available to support them? 


\section{Appendix C: Ethics Approval}

This is to inform you that the University of Windsor Research Ethics Board (REB), which is organized and operated according to the Tri-Council Policy Statement and the University of Windsor Guidelines for Research Involving Human Subjects, has granted approval to your research project on the date noted above. This approval is valid only until the Project End Date.

A Progress Report or Final Report is due by the date noted above. The REB may ask for monitoring information at some time during the project's approval period.

During the course of the research, no deviations from, or changes to, the protocol or consent form may be initiated without prior written approval from the REB. Minor change(s) in ongoing studies will be considered when submitted on the Request to Revise form.

Investigators must also report promptly to the REB:

a) changes increasing the risk to the participant(s) and/or affecting significantly the conduct of the study;

b) all adverse and unexpected experiences or events that are both serious and unexpected;

c) new information that may adversely affect the safety of the subjects or the conduct of the study.

Forms for submissions, notifications, or changes are available on the REB website: www.uwindsor.ca/reb. If your data is going to be used for another project, it is necessary to submit another application to the REB.

We wish you every success in your research. 


\section{Appendix D: Recruitment Email}

Hello, My name is Gelsea Pizzuto and I am a graduate student for the Education department at the University of Windsor. I am working under the supervision of Dr. Geri Salinitri while completing my Master's Thesis. You are receiving this email as a request for your participation.

The title of my research is Examining Factors, Supports, and Transitional Resources Among Students Attending Agency Schools in Southwestern Ontario. The purpose of this study is to examine factors, supports, and transitional resources among students in-risk, from the perspective of teachers who are currently working, or have worked, directly with students in-risk that are attending treatment in agency schools in Southwestern Ontario.

Participants who are currently working, or have worked as a teacher in an agency school setting, are invited to share their experiences working in agency schools. You must have a minimum of one-year experience working in an agency school setting.

If you volunteer to participate in the study, you will be asked to:

1) Partake in a single in-depth interview on your experience working with in-risk students that are attending treatment in agency schools in Southwestern Ontario. The lead researcher (Gelsea Pizzuto) will conduct, as well as audio-record the 
interview. The interview will last approximately 45 minutes, and will be completed at a time and location convenient for you.

2) Consent to the audio taping of interviews. This is a voluntary procedure and you are free to withdraw responses at any time. To withdraw statements, you must give verbal or written consent to the lead researcher, Gelsea Pizzuto. Your name and school will not be disclosed, and that taping will be kept confidential and securely stored by file number.

For participating in this study, you will receive a \$20.00 gift card from Amazon as compensation for your time and willingness to contribute to this research. If you are interested in participating in this research study, please email me at pizzutog@uwindsor.ca. An email will be sent back to you with a letter of information to verify your commitment, followed by a phone call to arrange a meeting time and location that is convenient for you. If you have any questions of concerns about this study, please feel free to contact me by email.

\section{Please respond by March 6, 2019 to confirm your willingness to participate.}

Sincerely, Gelsea Pizzuto 


\section{Appendix E: Letter of Consent to Participate in Research}

Title of Study:

Examining Factors, Supports, and Transitional Resources Among Students Attending

Agency Schools in Southwestern Ontario

You are asked to participate in a research study conducted by Gelsea Pizzuto, from the Faculty of Education at the University of Windsor under the supervision of Dr. Geri Salinitri. The results of this study will contribute to Gelsea Pizzuto's thesis work.

If you have any questions or concerns about the research, please feel to contact Gelsea Pizzuto from the University of Windsor by email. Dr. Salinitri can be reached by email or by phone.

\section{PURPOSE OF THE STUDY}

The purpose of this study is to examine factors, supports, and transitional resources among students in-risk, from the perspective of teachers who are working directly, or have worked directly, with students in-risk that are attending treatment in agency schools in Southwestern Ontario.

\section{PROCEDURES}

If you volunteer to participate in this study, you will be asked to:

1) Partake in a single in-depth interview on your experience working with in-risk 
students that are currently attending, or have attended treatment in agency schools in Southwestern Ontario. The lead researcher (Gelsea Pizzuto) will conduct, as well as audio-record the interview. The interview will last approximately 45 minutes, and will be completed at a time and location convenient for you.

2) Consent to the audio taping of interviews. Audio recording will be used during the interview to ensure data is accurate during the transcription phase. This is a voluntary procedure and you are free to withdraw responses at any time by requesting that the taping be stopped. To withdraw statements, you must give verbal or written consent to the lead researcher, Gelsea Pizzuto. Your name and school will not be disclosed, and that taping will be kept confidential and securely stored by file number.

\section{POTENTIAL RISKS AND DISCOMFORTS}

There is no intention on the part of the investigators to include any psychological or social risk to the participant. The interview is done on a volunteer basis. The interview will be audio recorded. You have the choice to refrain from answering any questions in the interview. You will be given a pseudonym and the name of your school will not be disclosed. The information that you provide will remain confidential and will not be shared with anyone besides Gelsea Pizzuto and Dr. Geri Salinitri. POTENTIAL BENEFITS TO PARTICIPANTS AND/OR TO SOCIETY

The study will expand on the research on agency schools in Southwestern Ontario. Data 
from the interviews will give insight into the efforts of the public education system to help students attending agency schools reach academic and overall success during their transition back into community schools. Moreover, it will provide you with the opportunity to reflect on your experience with the program.

\section{COMPENSATION FOR PARTICIPATION}

Participants will receive a $\$ 20.00$ gift card from Amazon as compensation for your time and willingness to contribute to this research.

\section{CONFIDENTIALITY}

Any information that is obtained in connection with this study and that can be identified with you will remain confidential and will be disclosed only with your permission. To ensure confidentiality, pseudonyms will be used for reporting and your name and the school that you belong to will only be available to the lead researcher (Gelsea Pizzuto) and Dr. Geri Salinitri. However, it is possible that a person who is strongly familiar with the school boards in Southwestern Ontario may be able to recognize the participants of the study. The report will be written in a manner that will minimalize this outcome. Audio recordings of the interviews will remain in a secure location in which only the researcher has access. Responses will be destroyed after September 1, 2019.

PARTICIPATION AND WITHDRAWAL 
This study is completely voluntary for all participants. You have the choice to refrain from answering any questions in the interview. Participants have the right to withdraw and amend their responses, without consequence, two weeks after transcription is sent to them by email. Participants will respond by sending back any changes, as well as signing the transcription. After this point, they no longer have the opportunity to withdraw from the study. Data analysis will be conducted after all interviews have been completed. Data will be kept indefinitely.

If for any reason, the researcher has the need to withdraw the participants from the research, the participant will be notified and an explanation will be given. FEEDBACK OF THE RESULTS OF THIS STUDY TO THE PARTICIPANTS

A summary of the findings and any post-study information will be made available via internet. Web address: https://scholar.uwindsor.ca/research-result-summaries/. Date when results are available: June 1, 2019. You will receive an email with information pertaining to the above website when the data is complete.

SUBSEQUENT USE OF DATA

This data may be used in subsequent studies, publications, and presentations.

\section{RIGHTS OF RESEARCH PARTICIPANTS}


If you have questions regarding your rights as a research participant, contact: Research Ethics Coordinator, University of Windsor, Windsor, Ontario, N9B 3P4; Telephone: XXXXXX-XXXX, ext.XXXX; e-mail: ethics@uwindsor.ca

SIGNATURE OF RESEARCH PARTICIPANT/LEGAL REPRESENTATIVE

I understand the information provided for the study Examining Factors, Supports, and Transitional Resources Among Students Attending Agency Schools in Southwestern Ontario as described herein. My questions have been answered to my satisfaction, and I agree to participate in this study. I have been given a copy of this form.

Name of Participant

Signature of Participant

Date

SIGNATURE OF INVESTIGATOR

These are the terms under which I will conduct research.

Signature of Investigator

Date 


\section{VITA AUCTORIS}

NAME:

PLACE OF BIRTH:

YEAR OF BIRTH:

EDUCATION:
Gelsea Pizzuto

Windsor, ON

1993

Riverside Secondary School, Ontario Secondary

Diploma., Windsor, ON, 2011

University of Windsor, Concurrent

B.A./B.Ed./E.C.E. Windsor, ON, 2017

University of Windsor, M.Ed., Windsor, ON, 2019 